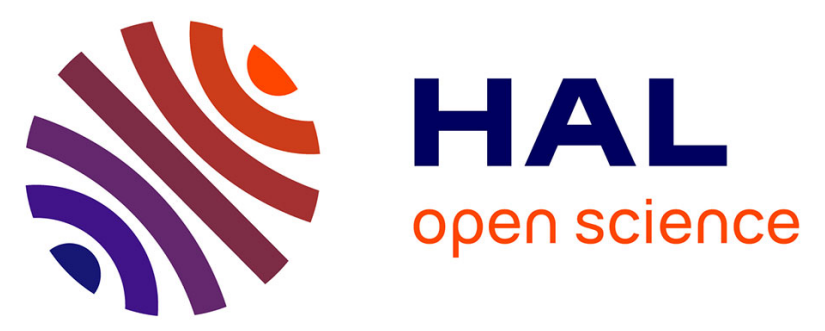

\title{
Experimental Investigation and Modeling of Early Flame Propagation Stages in Operating Conditions Representative of Modern High Efficiency Spark Ignition Engines
}

Alessio Dulbecco, Gregory Font, Fabrice Foucher, Pierre Brequigny

\section{To cite this version:}

Alessio Dulbecco, Gregory Font, Fabrice Foucher, Pierre Brequigny. Experimental Investigation and Modeling of Early Flame Propagation Stages in Operating Conditions Representative of Modern High Efficiency Spark Ignition Engines. SAE International journal of advances and current practices in mobility, 2020, 10.4271/2019-24-0073 . hal-02797513

\section{HAL Id: hal-02797513 \\ https://hal.science/hal-02797513}

Submitted on 3 Jul 2020

HAL is a multi-disciplinary open access archive for the deposit and dissemination of scientific research documents, whether they are published or not. The documents may come from teaching and research institutions in France or abroad, or from public or private research centers.
L'archive ouverte pluridisciplinaire HAL, est destinée au dépôt et à la diffusion de documents scientifiques de niveau recherche, publiés ou non, émanant des établissements d'enseignement et de recherche français ou étrangers, des laboratoires publics ou privés. 
archives-ouvertes

\section{Experimental Investigation and Modeling of Early Flame Propagation Stages in Operating Conditions Representative of Modern High Efficiency Spark Ignition Engines}

Alessio Dulbecco, Gregory Font, Fabrice Foucher, Pierre Brequigny

\section{To cite this version:}

Alessio Dulbecco, Gregory Font, Fabrice Foucher, Pierre Brequigny. Experimental Investigation and Modeling of Early Flame Propagation Stages in Operating Conditions Representative of Modern High Efficiency Spark Ignition Engines. SAE International journal of advances and current practices in mobility, SAE, 2020, 10.4271/2019-24-0073 . hal-02797513

\section{HAL Id: hal-02797513 \\ https://hal.archives-ouvertes.fr/hal-02797513}

Submitted on 3 Jul 2020

HAL is a multi-disciplinary open access archive for the deposit and dissemination of scientific research documents, whether they are published or not. The documents may come from teaching and research institutions in France or abroad, or from public or private research centers.
L'archive ouverte pluridisciplinaire HAL, est destinée au dépôt et à la diffusion de documents scientifiques de niveau recherche, publiés ou non, émanant des établissements d'enseignement et de recherche français ou étrangers, des laboratoires publics ou privés. 


\title{
Experimental Investigation and Modeling of Early Flame Propagation Stages in Operating Conditions Representative of Modern High Efficiency Spark Ignition Engines
}

\author{
Alessio Dulbecco, Gregory Font, Fabrice Foucher, Pierre Brequigny
}

\begin{abstract}
The present social context imposes effective reductions of transport greenhouse gases and pollutant emissions. To answer to this demand, car manufacturers adopted technologies such as downsizing, turbocharging, intense in-cylinder aerodynamics and diluted combustion process. In this context, to master mixture ignition is crucial to ensure an efficient heat release. To get to a clearer knowledge about the physics holding early stages of premixed mixture combustion, the PRISME institute in the framework of the French government research project ANR MACDOC generated a consistent experimental database to study ignition and spherical flame propagation processes in a constant volume vessel in laminar and turbulent environment. This allows to have a detailed description of the flame dynamics of an air / isooctane mixture depending on thermochemical properties of the mixture and nature of the diluent $(\mathrm{O} 2, \mathrm{H} 2 \mathrm{O}, \mathrm{CO} 2$ and synthetic stoichiometric Exhaust Gas Recirculation (EGR)), as well as on turbulent intensity and ignition energy. A system simulation model based on the Coherent Flame Model (CFM) approach was then setup at IFP Energies nouvelles (IFPEN) accounting for the influence of the flame stretch, through the integration of a non-linear formulation of the mixture Markstein number, and the flame wrinkling due to turbulence. The model allowed to have a deeper insight in the interpretation of experiments and to dissociate the interacting phenomena holding the combustion process. This modeling improving seems to be a necessary step to model next generation Spark Ignition engines operating under steady and transient conditions.
\end{abstract}

\section{Introduction}

One of the most important factors in premixed combustion modeling, and in particular in the CFM approach, is the laminar flame speed. This variable can be measured experimentally and it varies depending on the fuel nature, mixture temperature, pressure, equivalence ratio, dilution rate and dilution type. In literature several mathematical correlations fitting experiments are available for unstretched laminar flames. Nevertheless, the most extremes operating conditions attainable experimentally are quite far from what can be encountered when operating an Internal Combustion Engine (ICE), especially in terms of pressure and temperature. Furthermore, in engines, flames are stretched and it is known that stretched laminar flames velocities can be quite different of the corresponding unstretched values [13]. Experimental works available in literature on the determination of the laminar flame speeds for different thermochemical conditions, attaining extremes conditions of 20 bar in terms of pressure [21], and $450 \mathrm{~K}$ in terms of temperature [8], mainly relative to isooctane fuel, come from different research teams all around the world $[8,10,21,35,16,24]$. Regarding the impact of the stretch on the laminar flame speed, the above mentioned works consider a linear dependence between the two variables. This assumption is controverted in literature especially when dealing with diluted mixtures [23]. To go beyond the limitations encountered in experimental works and determine the behavior of the laminar flame speed of different fuel compositions [5] or extrapolate the understanding given by experiments to more severe thermochemical conditions, nowadays it is common to use complex chemistry solvers, which allow to determine species reaction rates of chemical mechanism accounting for hundreds of species and thousands of reactions [39]; nevertheless, this approach remains a pure speculation, being the chemical mechanisms themselves validated on intervals of pressure and temperature which are quite far from real conditions inside ICE combustion chambers. Furthermore, in ICEs flame propagates in a turbulent flow field and flame is wrinkled by turbulence. Usually, in literature, when dealing with turbulent flame propagation, flame stretch is commonly not accounted for. The goal of this paper is to introduce in the turbulent combustion modeling approach adopted within the CFM1D combustion model [53] a consistent description of the effective flame speed behavior accounting for stretch for laminar and turbulent propagating conditions. In details, after a short remind regarding premixed flame propagation theory, the experimental setup and generated database, used to identify the model correlations as well as for validation purposes, are presented [17,45]. Then, it will be presented in a first time the modeling approach adopted to account for the flame stretch impact on laminar flame propagation, by using a theory based on a non-linear dependence of these two variables, and in a second time the modeling approach adopted to account for the flame stretch impact on turbulent flame propagation, by maintaining the non-linear theory.

\section{Remind about premixed propagating flames theory}

In this section, the basics of the theory relative to premixed divergent flame combustion, which is the common confirmation in Spark Ignition (SI) ICE, are reminded.

\section{Laminar flame speed of divergent flames}

Different definitions of flame velocity can be given to deal with laminar flame speed $[3,30]$. A brief remind is given below.

\section{Absolute Velocity}

The absolute velocity, $S_{b}$, represents the flame front velocity with respect to the burned gas coordinate system, which stay immobile. $S_{b}$ is defined as: 


$$
S_{b}=\frac{d R_{b}}{d t}
$$

Where $R_{b}$ is the burned gas volume radius, here supposed as being a spherical region. This is an interesting variable as it can be directly compared to experimental observations obtained by means of techniques such as shadowgraph [18], Schlieren [9], Raman [27] or tomography [9], both by following an iso-value of temperature, or the maximum value of the derivative of one of the above-mentioned variables.

\section{Displacement Velocity}

The displacement velocity, $S_{d}$, represents the flame velocity with respect to the local flow field:

$$
S_{d}=S_{b}-\vec{u} \cdot \vec{n}
$$

where $\vec{u}$ is the gas velocity and $\vec{n}$ is the flame front surface normal vector pointing towards the fresh gas. For a spherical diverging flame, this variable is very hard to measure because fresh gas is moving and the flow field is accelerated by the flame front. According to [30] by means of the continuity equation, it is possible to write the displacement velocity as the product of the absolute velocity and the ratio of burned and unburned gas densities, respectively $\rho_{b}$ and $\rho_{u}$ :

$$
S_{d}=S_{b} \frac{\rho_{b}}{\rho_{u}}
$$

\section{Consumption Velocity}

The consumption velocity, $S_{c}$, represents the speed at which reactants are consumed. For a spherical flame configuration it holds:

$$
S_{c}=-\frac{1}{\rho_{u} Y_{F_{u}} R_{b}} \int_{0}^{R_{b}} \&_{F} r^{2} d r
$$

where $Y_{F_{u}}$ is the fuel mass fraction in unburned gas and $\&$ is the fuel reaction rate. By knowing $S_{c}$, it is possible to compute the evolution of the burned gas mass, $\mathrm{m}_{\mathrm{b}}$, in time by mean of the relation below [3]:

$$
\frac{d m_{b}}{d t}=4 \pi \rho_{u} S_{c} R_{b}^{2}
$$

where:

$$
m_{b}=\int_{0}^{V_{b}} \rho_{b} d V_{b}
$$

in which $V_{b}$ represents the burned gas volume. For infinitely thin flame fronts and a burned gas density which does not vary in time, it holds:

Page 2 of 20

$$
S_{d}=S_{c}=\frac{\rho_{b}}{\rho_{u}} \frac{d R_{b}}{d t}
$$

The burning velocity of a free planar flame is the called unstretched laminar flame speed, $S_{l}^{O}$.

\section{Stretch impact on laminar flame speed}

The stretch is defined by the fractional rate of change of the flame surface, $A$ :

$$
K=\frac{1}{A} \frac{d A}{d t}
$$

In the specific case of a spherical flame configuration of radius $R$ and surface $A=\frac{4}{3} \pi R^{3}$, the stretch expression holds:

$$
K=\frac{2}{R} \frac{d R}{d t}=\frac{2}{R} S_{b}
$$

The influence of the stretch, $K$, on the unstretched laminar flame speed, $S_{l}^{0}$, is defined by means of the Markstein length, $L_{u}$ or $L_{b}$ depending on if defined with respect to unburned or burned gas, respectively. This influence can be expressed by means of a nonlinear relation relying the flame displacement speed, $S_{b}$, relative to burned gas to the stretch as:

$$
\left(\frac{S_{b}}{S_{b}^{0}}\right) \ln \left(\left(\frac{S_{b}}{S_{b}^{0}}\right)^{2}\right)=-\frac{L_{b}}{S_{b}^{0}} K
$$

For little values of flame stretch, the relation above can be simplified and approximated by means of a linear formulation of the laminar flame speed dependence on stretch as it follows:

$$
S_{b}=S_{b}^{0}-L_{b} K
$$

Figure 1 compares the non-linear and linear formulations to experiments, for two different flame propagation conditions, [37]. As shown, the two approximations can give a quite accurate representation of experiments for certain conditions (top), but for other conditions (bottom) the linear approximation can become a raw approximation for both high and low stretch values when compared to experiments. 

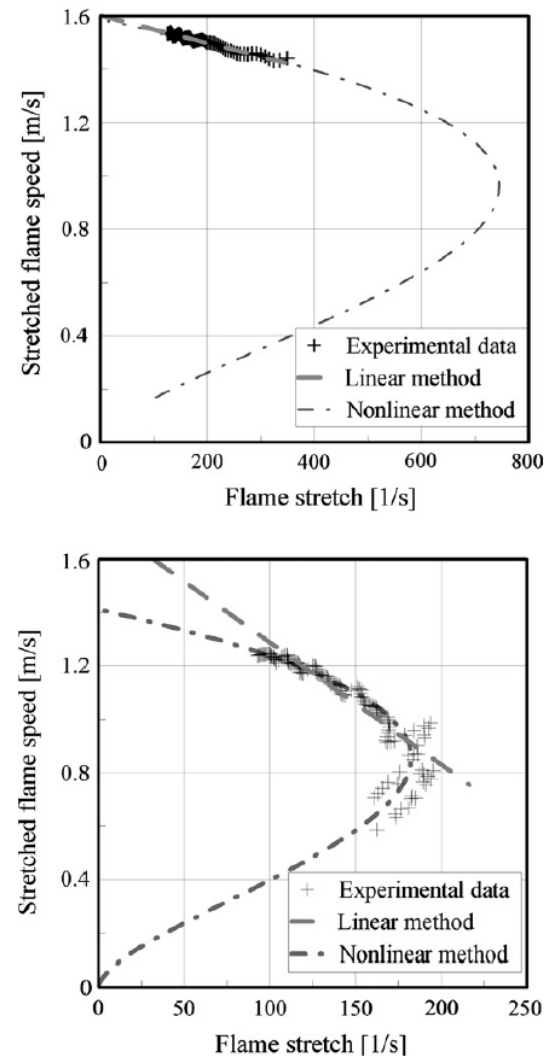

Figure 1. Evolution of the stretched propagation speed with stretch for two equivalence ratios: $\mathrm{f}=0.8$ (top) and $\mathrm{f}=1.3$ (bottom) relative to reactive mixtures of CH4/air at the pressure of 1 bar and a temperature of $300 \mathrm{~K}$, [37].

\section{Turbulent divergent flames}

This section introduces the notion of flame surface density in the case of a spherical flame front by means of simple geometrical considerations. As shown in Figure 2, the flame radius of the burned gas region corresponds to the radius of the sphere having a volume $V_{b}$ and a surface $A_{m}$. The mean flame surface, $A_{m}$, is related to the total surface, $A$, by means of the flame wrinkling, $\Xi$, according to the following relation:

$$
A=\Xi A_{m}
$$

Accordingly:

$$
\Xi=\frac{A}{A_{m}}=\frac{A}{4 \pi R_{b}^{2}}
$$

The total burned gas mass, $m_{b}$, is related to the flame volume by means of the following relation:

$$
m_{b}=\rho_{b} V_{b}=\rho_{b} \frac{4}{3} \pi R_{b}^{3}
$$

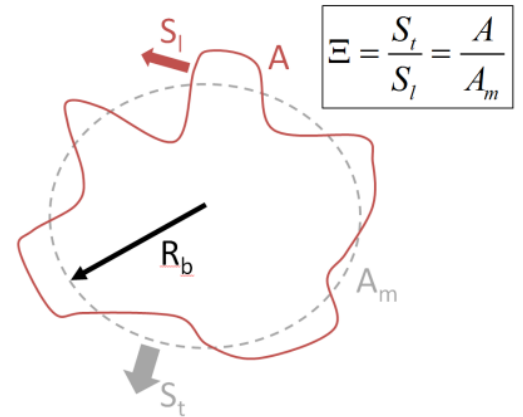

Figure 2. Definitions of the flame variables: burned gas volume radius, $R_{b}$, total flame surface, A, mean flame surface, $A_{m}$, turbulent flame speed, $S_{t}$, laminar flame speed, $\mathrm{S}_{1}$, flame wrinkling, $\Xi$.

The evolution of the burned gas mass can be expressed through the mass conservation equation as:

$$
\frac{d m_{b}}{d t}=\frac{d\left(\rho_{b} V_{b}\right)}{d t}=\rho_{u} S_{L} \pi R_{b}^{2} \Xi
$$

By using Equation (14), the evolution of the burned gas mass can be expressed also as:

$$
\frac{d m_{b}}{d t}=\rho_{b} 4 \pi R_{b}^{2} \frac{d R_{b}}{d t}+\frac{4}{3} \pi R_{b}^{3} \frac{d \rho_{b}}{d t}
$$

By combining Equation (15) and Equation (16), the evolution of the burned gas radius in time holds:

$$
\frac{d R_{b}}{d t}=\frac{\rho_{u}}{\rho_{b}} S_{l} \Xi-\frac{R_{b}}{3 \rho_{b}} \frac{d \rho_{b}}{d t}
$$

By supposing an isentropic process and neglecting the variation of pressure, the above equation holds:

$$
\frac{d R_{b}}{d t}=(1+\theta) S_{l} \Xi
$$

in which:

$$
\theta=\frac{\rho_{u}}{\rho_{b}}-1
$$

where $\theta$ represents the thermal expansion rate.

\section{Experimental Setup}

Setup description.

\section{Experimental Database}

Database structure description.

Table 1. Investigation conditions for turbulent isooctane/air.

\begin{tabular}{|l|l|l|l|l|}
\hline Temp. & Press. & $\phi$ & Diluent & u' $[\mathrm{m} / \mathrm{s}]$ \\
\hline
\end{tabular}




\begin{tabular}{|c|c|c|c|c|c|c|c|c|c|}
\hline$[\mathrm{K}]$ & [bar] & & [\%] & 0.7 & 1.04 & 1.39 & 1.73 & 2.08 & 2.43 \\
\hline 323 & 1 & 1 & 0 & & & $\mathrm{X}$ & & & \\
\hline 373 & 1 & 1 & 0 & & & $\mathrm{X}$ & & & \\
\hline \multirow{22}{*}{423} & \multirow{19}{*}{1} & 0.8 & 0 & & & $\mathrm{X}$ & & & \\
\hline & & 0.9 & 0 & & & $\mathrm{X}$ & & & \\
\hline & & \multirow{11}{*}{1} & 0 & $X$ & $\mathrm{X}$ & $\mathrm{X}$ & $\mathrm{X}$ & $X$ & $\mathrm{X}$ \\
\hline & & & $5-\mathrm{N} 2$ & & & $\mathrm{X}$ & & & \\
\hline & & & $10-\mathrm{N} 2$ & & & $\mathrm{X}$ & & & \\
\hline & & & $15-\mathrm{N} 2$ & & & $\mathrm{X}$ & & & \\
\hline & & & $5-\mathrm{H} 2 \mathrm{O}$ & & & $\mathrm{X}$ & & & \\
\hline & & & $10-\mathrm{H} 2 \mathrm{O}$ & & & $\mathrm{X}$ & & & \\
\hline & & & $5-\mathrm{H} 2 \mathrm{O}$ & & & $\mathrm{X}$ & & & \\
\hline & & & $10-\mathrm{H} 2 \mathrm{O}$ & & & $\mathrm{X}$ & & & \\
\hline & & & 5-EGR & & & $X$ & & & \\
\hline & & & 10-EGR & & & $\mathrm{X}$ & & & \\
\hline & & & 15-EGR & & & $\mathrm{X}$ & & & \\
\hline & & 1.1 & 0 & & & $\mathrm{X}$ & & & \\
\hline & & 1.2 & 0 & & & $\mathrm{X}$ & & & \\
\hline & & 1.3 & 0 & & & $\mathrm{X}$ & & & \\
\hline & & 1.4 & 0 & & & $\mathrm{X}$ & & & \\
\hline & & 1.5 & 0 & & & $\mathrm{X}$ & & & \\
\hline & & 1.6 & 0 & & & $\mathrm{X}$ & & & \\
\hline & 3 & 1 & 0 & & & $\mathrm{X}$ & & & \\
\hline & 5 & 1 & 0 & & & $\mathrm{X}$ & & & \\
\hline & 10 & 1 & 0 & & & $\mathrm{X}$ & & & \\
\hline 473 & 1 & 1 & 0 & & & $\mathrm{X}$ & & & \\
\hline
\end{tabular}

\section{Simulation Approach}

In this section the focus is on the understanding and representation of the premixed flame propagation within a reactive mixture by accounting for major factors impacting the flame behavior such as temperature, pressure, mixture equivalence ratio, dilution rate and diluent composition. For this, the developments are based and validated on experiments representative of the multi-dimensional domain in which such major factors vary.

\section{State of the art}

The CFM1D combustion model [53] allows to adopt, depending on the fuel nature, different correlations for laminar flame speed available in literature. Available flame correlations for isooctane, which is the fuel concerned by this study, are:

- The flame speed correlation for isooctane proposed by [49],

- The flame speed correlation for isooctane-ethanol mixture proposed by [50].

The major limitation is that the present approach does not account for any flame stretch impact on combustion.

\section{Laminar combustion modeling}

As introduced above, flame speed correlations are obtained by fitting mathematical expressions on the set of experimental results. The experimental database represented by the set of data collected in [18] and [45] is rich in terms of information and exhaustive in terms of operating condition parametric variations. For these reasons the flame correlation for unstretched laminar flame speed based on nonlinear flame speed dependence on stretch proposed in [45] was integrated in the combustion model. This flame correlation allows to account for flame sensitivity to mixture thermodynamic conditions expressed in terms of pressure, $P_{i n i}$, temperature, $T_{i n i}$, equivalence ratio, $\phi$, and molar fraction of oxygen in ambient air, $v_{\mathrm{O} 2}$ :

$$
\begin{gathered}
S_{l}^{0}=S_{l_{r e f}}^{0}\left(\frac{T_{i n i}}{T_{r e f}}\right)^{\alpha_{S}}\left(\frac{P_{i n i}}{P_{r e f}}\right)^{\beta_{S}} \\
S_{l_{r e f}^{0}}^{0}=A+B\left(\phi-\phi_{m}\right)+C\left(\phi-\phi_{m}\right)^{2}+ \\
D\left(\phi-\phi_{m}\right)^{3}+E\left(\phi-\phi_{m}\right)^{4} \\
\alpha_{S}=\alpha_{1}+\alpha_{2}\left(\phi-\phi_{m}\right) \\
\beta_{S}=\beta_{1}+\beta_{2}\left(\phi-\phi_{m}\right)
\end{gathered}
$$

where $P_{\text {ref }}$ and $T_{\text {ref }}$ are respectively the reference pressure and temperature taken at $P_{r e f}=1$ bar and $T_{r e f}=423 \mathrm{~K} . S_{l_{r e f}}^{0}$ correspond at the laminar burning velocity under these reference conditions in terms of pressure and temperature. All values of correlation parameters $A, B, C, D, E, \alpha_{1}, \alpha_{2}, \beta_{1}, \beta_{2}$ and $\phi_{m}$ are given in Table 2. In this correlation, temperature is expressed in $\mathrm{K}$, pressure in bar and laminar burning velocity in $\mathrm{cm} / \mathrm{s}$.

Table 2. Numerical values of the parameters in Equation (20).

\begin{tabular}{|c|c|}
\hline Parameter & Value \\
\hline A & 55.42 \\
B & $-2.22 \mathrm{e}-14$ \\
C & -171.90 \\
D & 74.61 \\
E & 153.70 \\
$\phi_{\mathrm{m}}$ & 1.10 \\
$\alpha_{1}$ & 1.58 \\
$\alpha_{2}$ & 0.04 \\
$\beta_{1}$ & -0.203 \\
$\beta_{2}$ & $-9.44 \mathrm{e}-7$ \\
\hline
\end{tabular}

Dilution effect of $\mathrm{CO} 2, \mathrm{H} 2 \mathrm{O}$ and synthetic EGR on the laminar flame speed is accounted for by adding an additional term to the laminar flame speed correlation, Equation (20); this new contribution is detailed in Equation (21): 


$$
\begin{gathered}
S_{l}^{0}\left(v_{O 2}\right)=S_{l}^{0}\left(v_{O 2_{\text {ref }}}\left(\frac{v_{O 2}}{v_{O 2_{\text {ref }}}}\right)^{\gamma_{-i}}\right. \\
v_{O 2}=\left(\frac{n_{O 2 \text { (air) }}}{n_{O 2 \text { (air) }}+n_{N 2(\text { air })}+n_{\text {diluent }}}\right) \cdot 100 \\
\gamma_{-i}=\gamma_{1_{-} i}+\gamma_{2_{-i} i}\left(\phi-\phi_{m}\right)
\end{gathered}
$$

where $i$ represents the diluent composition and the coefficients $\gamma_{1_{-} i}$ and $\gamma_{2_{-i}}$ are given in Table 3. $v_{O 2}$ corresponds to the oxygen volume in the synthetic ambient air used during experiments, $v_{O 2_{r f}}$ is equal to $20.9 \%$ in volume and corresponds to the oxygen volume fraction in air.

Table 3. Numerical values of the parameters in Equation (21); index i represents the diluent composition.

\begin{tabular}{|c|c|c|c|}
\hline $\mathrm{i}=$ & $\mathrm{CO} 2$ & $\mathrm{H} 2 \mathrm{O}$ & EGR \\
\hline$\gamma_{\iota_{-} 1}$ & 7.523 & 3.786 & 4.079 \\
$\gamma_{\left\llcorner \_\right.}$ & 0.365 & 0.473 & -1.354 \\
\hline
\end{tabular}

The Markstein length represents the dependence of the laminar flame propagation velocity on the stretch rate $K$, Equation (10) and Equation (11). Here a nonlinear method is used to determine the Markstein length. The following correlation, Equation (22), gives the value of Markstein length for non-diluted mixtures; the correlation is valid for pressures lower than 5 bar and equivalence ratios varying in the interval between 0.9 and 1.2:

$$
\begin{gathered}
L_{b}=L_{b_{r e f}}\left(\frac{T_{i n i}}{T_{r e f}}\right)^{\alpha_{L}}\left(\frac{P_{i n i}}{P_{r e f}}\right)^{\beta_{L}} \\
L_{b_{r e f}}=M \phi+N
\end{gathered}
$$

where coefficients $M, N, \alpha_{L}$ and $\beta_{L}$ are given in Table 4. $L_{b_{\text {ref }}}$ represents the Markstein length at the reference pressure of 1 bar and temperature of $423 \mathrm{~K}$. In this correlation, temperature is expressed in $\mathrm{K}$, pressure in bar and the Markstein length in $\mathrm{mm}$.

Table 4. Numerical values of the parameters in Equation (22).

\begin{tabular}{|c|c|c|c|c|}
\hline Parameters & $\mathrm{M}$ & $\mathrm{N}$ & $\alpha_{\mathrm{L}}$ & $\beta_{\mathrm{L}}$ \\
\hline Value & -1.45 & 2.23 & -0.58 & -0.71 \\
\hline
\end{tabular}

Dilution effect of $\mathrm{CO} 2, \mathrm{H} 2 \mathrm{O}$ and synthetic EGR on the Markstein length is accounted for by means of the equations below:

$$
\begin{gathered}
L_{b}\left(v_{O 2}\right)=L_{b}\left(v_{O 2_{r e f}}\right)\left(\frac{v_{O 2}}{v_{O 2_{r e f}}}\right)^{\gamma_{L_{-} i}} \\
\left.\gamma_{L_{-i}}=\gamma_{L 1_{-i}}\left(\frac{P_{i n i}}{P_{r e f}}\right)^{-1} e^{\left(\gamma_{L 2_{-} i} \tau \frac{P_{i n i}}{P_{r e f}}\right.}\right)
\end{gathered}
$$

where $\tau$ is the dilution rate defined as above-mentioned and the values of coefficients $\gamma_{L_{-} i}$ and $\gamma_{L_{-} i}$ are given Table 5. The Markstein length correlation is considered valid only for dilution rates where flames development was observed (especially at 1 bar).

Table 5. Numerical values of the parameters in Equation (23); index i represents the diluent composition.

\begin{tabular}{|c|c|c|c|}
\hline $\mathrm{i}=$ & $\mathrm{CO} 2$ & $\mathrm{H} 2 \mathrm{O}$ & $\mathrm{EGR}$ \\
\hline$\gamma_{\mathrm{L} 1 \_1}$ & -7.44 & -5.619 & -2.721 \\
$\gamma_{\mathrm{L} 2 \_\mathrm{i}}$ & 0.95 & 0.997 & 1.547 \\
\hline
\end{tabular}

Available useful information recorded during experiments for numerical approach development and validation is:

- unstretched laminar flame speed,

- Markstein length,

- evolution of the mean flame radius in time,

- uncertainty on the mean flame radius,

- evolution of the mean flame velocity in time,

- uncertainty on the mean flame velocity,

- flame stretch,

- $\quad$ shot by shot experimental results.

The flame speed dependence on unburned gas temperature, pressure, equivalence ratio, diluent composition and dilution rate was integrated into the CFM1D combustion model. It has to be noted that the correlation fits experimental results on the investigated domain; accordingly, all extrapolation have to be managed consciously in order to retrieve the physics phenomenology and avoid non-physical interpretations. For what concerns the correlation detailed by Equations (20) and Equation (21), no measure was taken to manage extrapolations related to temperature, pressure and dilution rate; this because, for the these variables, phenomenology was retrieved and no other experimental evidences were available to modify them; furthermore, for the dilution rate variable, as the tested limits approach the maximum dilution rate adopted in ICEs, the extrapolation of the correlation behavior will be generally relatively reduced. In what concerns the extrapolation of the flame correlation vis-à-vis the equivalence ratio, it must be guaranteed that flame speed tends to zero when approaching the inflammability limits of the mixture; for this, for a given equivalence ratio out of the domain of the correlation validity domain, a linear interpolation of the laminar flame speed value given by the correlation for its limit equivalence ratio and zero, related to the lower/higher inflammability limit, is performed; lower and high inflammability limits were supposed to be unique for every operating condition. Furthermore, these inflammability limits were considered as being less restrictive than what can be expected by simply extrapolating the experimental laminar flame speed curve, the reason being to guarantee a more robust behavior of the combustion model, from a numerical

Page 5 of 20 
viewpoint; in details the retained values are 0.3 for the lower inflammability equivalence ratio and 2.3 for the higher inflammability equivalence ratio, Figure 3 to Figure 5.

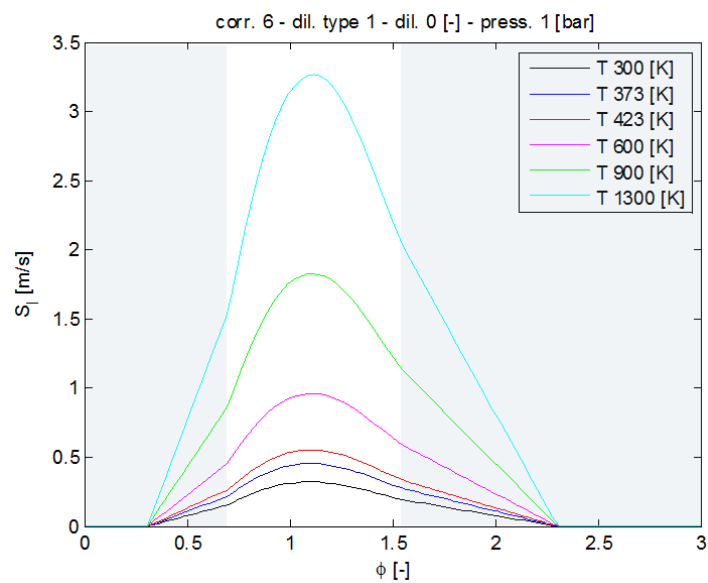

Figure 3. Evolution of the unstretched laminar flame speed as a function of the equivalence ratio for different temperatures; pressure is equal to $1 \mathrm{bar}$; there is no dilution. Greyed regions refer to the extrapolated behavior of the correlation.

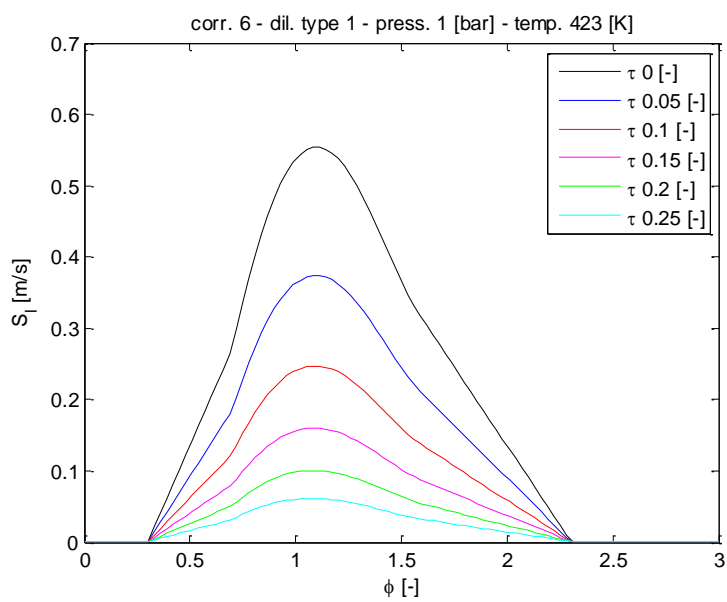

Figure 4. Evolution of the unstretched laminar flame speed as a function of the equivalence ratio for different dilution rates; pressure is equal to 1 bar; temperature is equal to $423 \mathrm{~K}$.

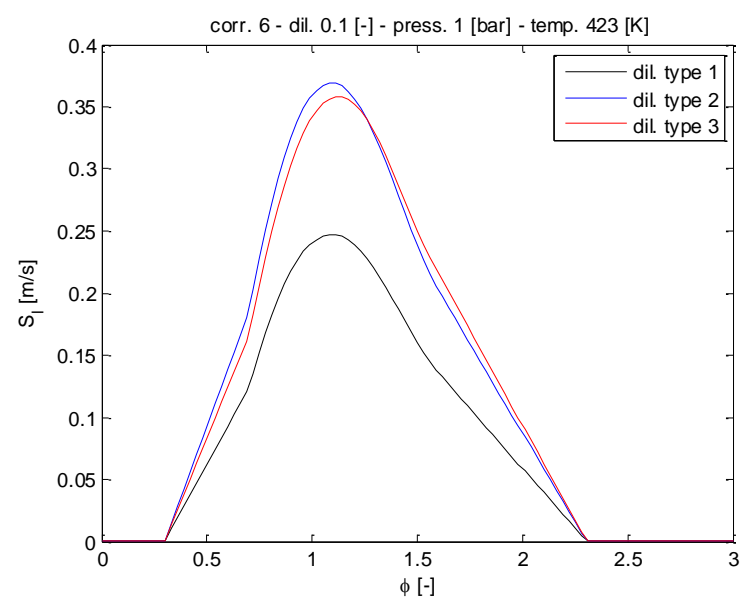

Figure 5. Evolution of the unstretched laminar flame speed as a function of the equivalence ratio for different diluent compositions; pressure is equal to 1 bar; dilution rate is equal to $10 \%$ in volume.

All the assumptions listed in the previous paragraph are illustrated by Figure 6 to Figure 9, in which the behavior of the laminar flame speed correlation is shown as a function of the different operating conditions covering all the operating domain that can be encountered in engine applications.
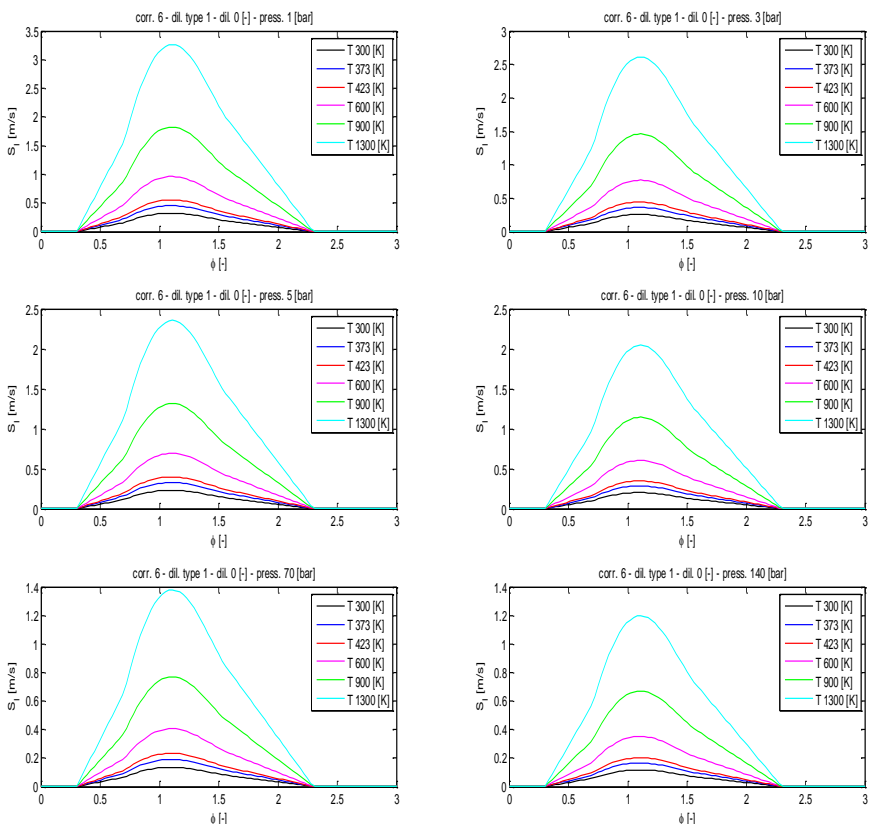

Figure 6. Evolution of the unstretched laminar flame speed as a function of the equivalence ratio for different temperatures; pressure is varied for the different plots from 1 to 140 bar; there is no dilution. 

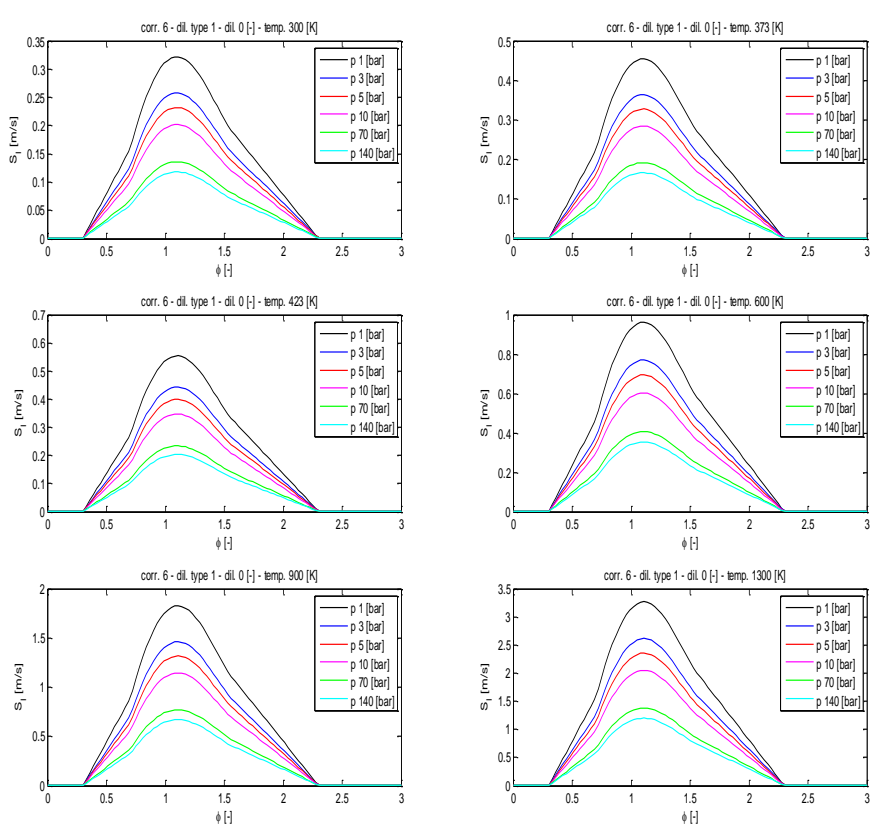

Figure 7. Evolution of the unstretched laminar flame speed as a function of the equivalence ratio for different pressures; temperature is varied for the different plots from 300 to $1300 \mathrm{~K}$; there is no dilution.
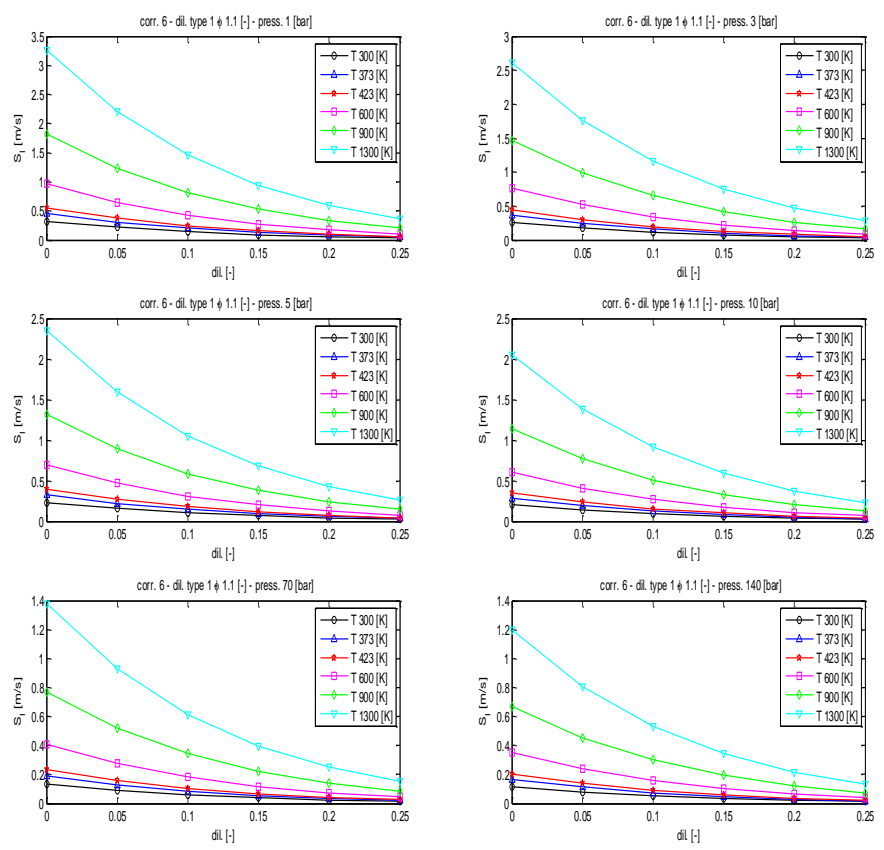

Figure 8. Evolution of the unstretched laminar flame speed as a function of the dilution rate for different temperatures; pressure is varied for the different plots from 1to 140 bar; mixture equivalence ratio is 1.1 ; diluent is composed by $\mathrm{H} 2 \mathrm{O}$.

Page 7 of 20

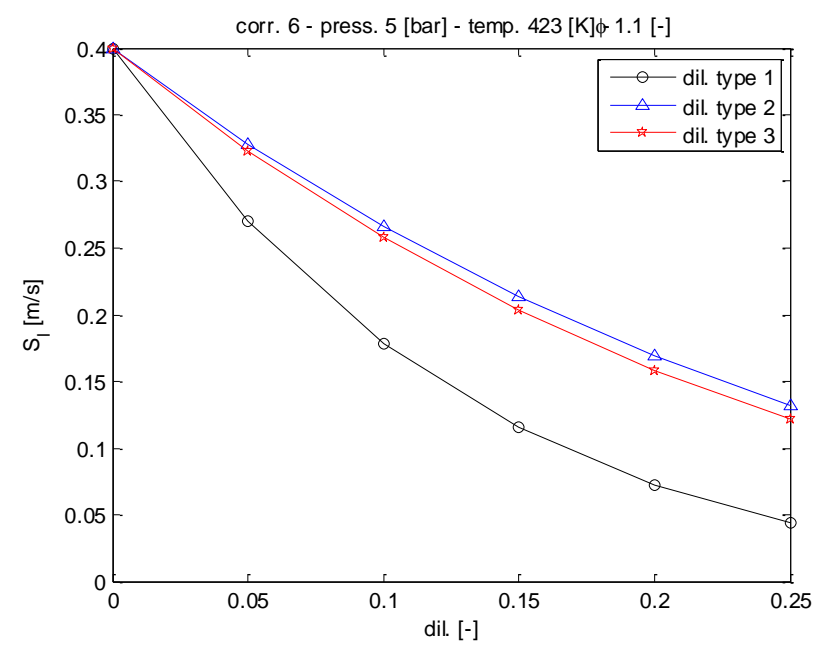

Figure 9. Evolution of the unstretched laminar flame speed as a function of the dilution rate for different dilution compositions; pressure is 5 bar; mixture equivalence ratio is 1.1 ; temperature is $423 \mathrm{~K}$.

\section{Turbulent combustion modeling}

The database relative to turbulent flame speed was generate by measuring spherical expanding flames by means of a shadowgraph method [17]. Isooctane/air mixtures at different temperature (from 323 to 473 bar K), different pressures (from 1 to 10 bar), different equivalence ratios (from 0.8 to 1.6), different dilution rates (from 0 to $15 \%$ in volume), different dilution composition (N2, H2O, CO2 and synthetic EGR) and different turbulence intensities, expressed in terms of turbulent velocity fluctuation, $u^{\prime}$, (from 0.7 to $2.4 \mathrm{~m} / \mathrm{s}$ ) were investigated. $\mathrm{CO} 2, \mathrm{H} 2 \mathrm{O}$ and EGR were used as diluent over dilution range from 5 to $25 \%$ in volume. The characterization of turbulence in the constant volume combustion chamber was performed and detailed in [19]. All the variations were performed around a reference point, which is characterized by the following operating conditions: temperature $423 \mathrm{~K}$, pressure 1 bar, equivalence ratio 1.0, dilution rate $0 \%$, turbulent intensity $1.4 \mathrm{~m} / \mathrm{s}$. The complete set of experiments is presented in Table 1.

Available useful information recorded during experiments for numerical approach development and validation is:

- evolution of the mean flame radius in time,

- uncertainty on the mean flame radius,

- evolution of the mean flame velocity in time,

- uncertainty on the mean flame velocity,

- $\quad$ shot by shot experimental results.

The CFM1D modeling approach to account for the impact of turbulence on combustion is detailed in [46]. According to this approach, turbulence vortices impact the flame front by wrinkling it with an efficiency which depends on turbulent field characteristics, namely the integral length scale, $l_{t}$, and the turbulent velocity intensity, $u$ ', and the premixed flame properties, namely the flame thickness, $\delta_{1}$, and the laminar flame speed, $S_{1}$; the wrinkling efficiency function describing the turbulence-flame interaction is the one proposed in [47]. The turbulent flame surface $A$ is written as the product of a mean surface $A_{m}$ and the flame front wrinkling factor $\Xi$, Equation (10). The flame wrinkling factor evolution is given by a physical equation describing the progressive transition from the 
laminar kernel to the fully turbulent flame. This equation was obtained by reduction of the $3 \mathrm{D}$ equation for the flame surface density [46] and includes the unsteady effect of the turbulent flow on the flame stretch through the efficiency function $\Gamma$ proposed in [47]:

$$
\begin{aligned}
\frac{1}{\Xi} \frac{d \Xi}{d t}= & \Gamma\left(\frac{u^{\prime}}{S_{l}}, \frac{l_{t}}{\delta_{l}}\right) \frac{u^{\prime}}{l_{t}}\left(\frac{\Xi_{e q u}-\Xi}{\Xi_{e q u}-1}\right) \\
& -\frac{2}{R_{b}}(1+\theta)(\Xi-1) S_{l}
\end{aligned}
$$

$u^{\prime}$ is the instantaneous velocity fluctuation, $l_{t}$ is the integral length scale, $\delta_{l}$ is the laminar flame thickness estimated using Blint's correlation [55], $\theta=\frac{\rho_{u}}{\rho_{b}}$ is the thermal expansion rate, $R_{b}=\left(\frac{3 V_{b}}{4 \pi}\right)^{\frac{1}{3}}$ is the current mean radius of burnt gases and $\Xi_{\text {equ }}$ corresponds to the $\Xi$ value when an equilibrium is reached between turbulence and flame wrinkling $\Xi$ [33]. The main unknowns of the problem finally correspond the turbulent flow field properties $u$ ' and $l_{t}$. No specific turbulence modeling was adopted in this study: it was supposed that, at least for the time interval during the observed flame propagation, turbulent intensity remain constant as well as integral length scale. It was shown in [48] that mean flame stretch must be accounted for correctly estimating the laminar flame speed propagating in a turbulent flow field. Accordingly, to adapt the approach presented in [46] to spherical outward propagating premixed flames in a turbulent flow field, regarding the inputs of the wrinkling efficiency function, the following hypothesis were done:

- the mean flame surface can be assimilated to an expanding sphere,

- the mean stretch depends on the radius of the mean flame surface,

- the flame wrinkling has global effect on the computation of the mean laminar flame speed that is negligible; that is the related positive and negative curvature effects compensate with each other.

\section{Simulation Results}

In this section simulation results are plotted against experiments to highlight the importance to account for stretch impact on flame propagation.

\section{Flame stretch impact}

In what follow, from Figure 10 to Figure 13 are shown results of simulations reproducing the laminar combustion processes taking place in a constant volume combustion vessel with the same characteristics of that used in experiments; results are compare to experimental data. The operating conditions refer to the reference conditions that were retained to generate the experimental database, that is temperature $=423 \mathrm{~K}$, pressure $=1$ bar, $\phi=1.1$ and no dilution. According to [17], the ignition device, in this case two electrodes, and the ignition energy transferred to the reactive mixture at sparking time do not have a neutral impact on the development of the very early flame kernel and the flame propagation, especially in the interval of time interesting flame radii lower than 5 to $6 \mathrm{~mm}$; this evolution, more related to ignition physics than to flame propagation

Page 8 of 20 physics, becomes negligible for flame radii higher than $5 \mathrm{~mm}$, Figure 10. As this work mainly focuses on flame propagation, the model development and validation were focused on the free flamepropagation regime.

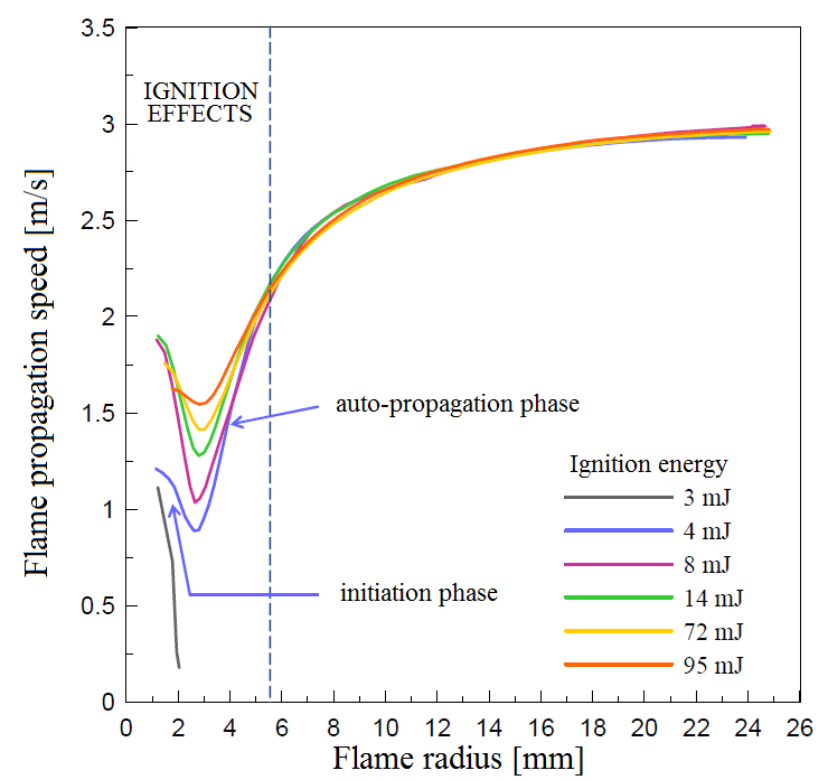

Figure 10. Experimental evolution of the flame propagation velocity as a function of the flame radius for different ignition energy values, [17].

In this study, the work is focused on the free propagation phase of the flame. Accordingly, to judge the quality of the modeling approach, the analysis will be focused on the flame radius evolution out of the region concerned by ignition. Accordingly, to have an easier comparison of experiments with simulation results, a time offset is applied to experimental results for shifting in time the measured variables, in order to have a superposition of simulated and measured flame radii at a given value of the radii. In what follows, taking into account that each experiment has its own minimum radius value which can differ from the others, in order to fix a general rule for all experiments analysis, it was decided to proceed as it follows:

- $\quad$ to determine the maximum among the minimum radii recorded experimentally,

- to use this value as radius coordinate to quantify the temporal shift of each experiment. 


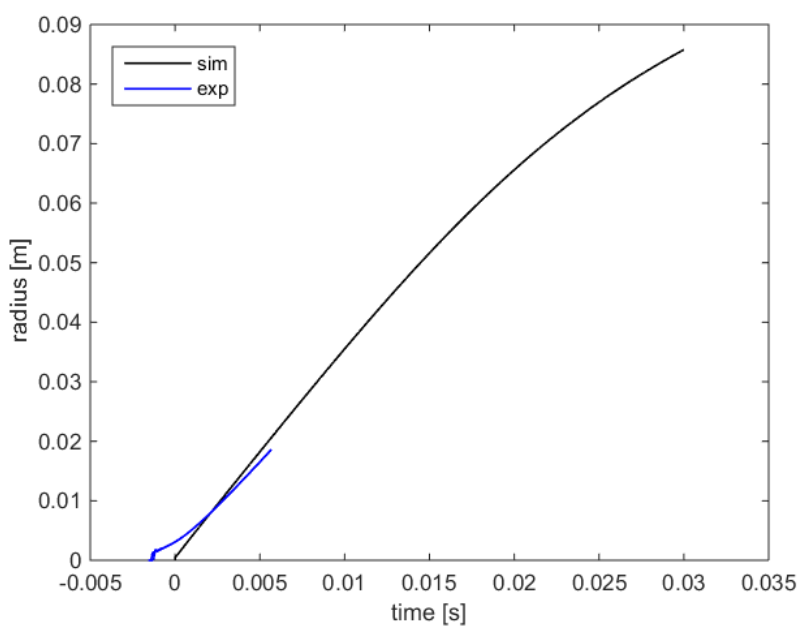

(a)

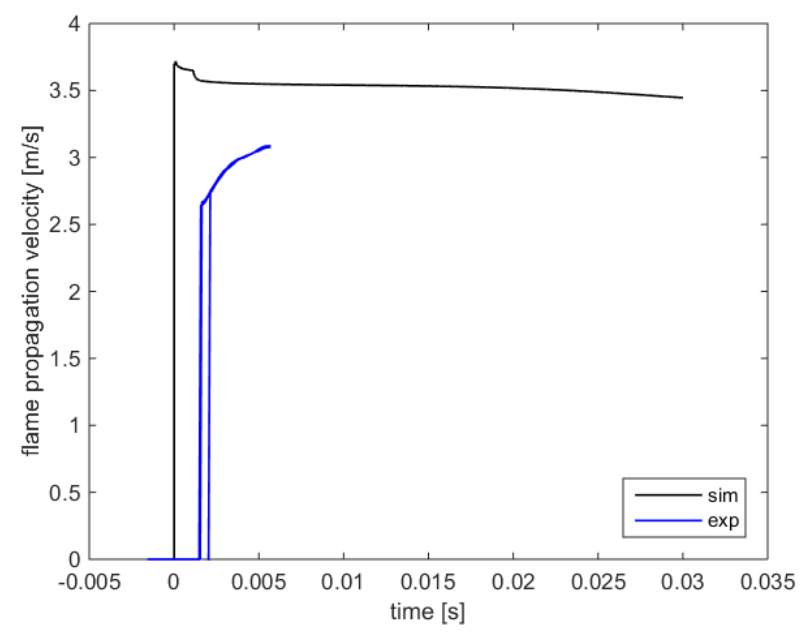

(b)

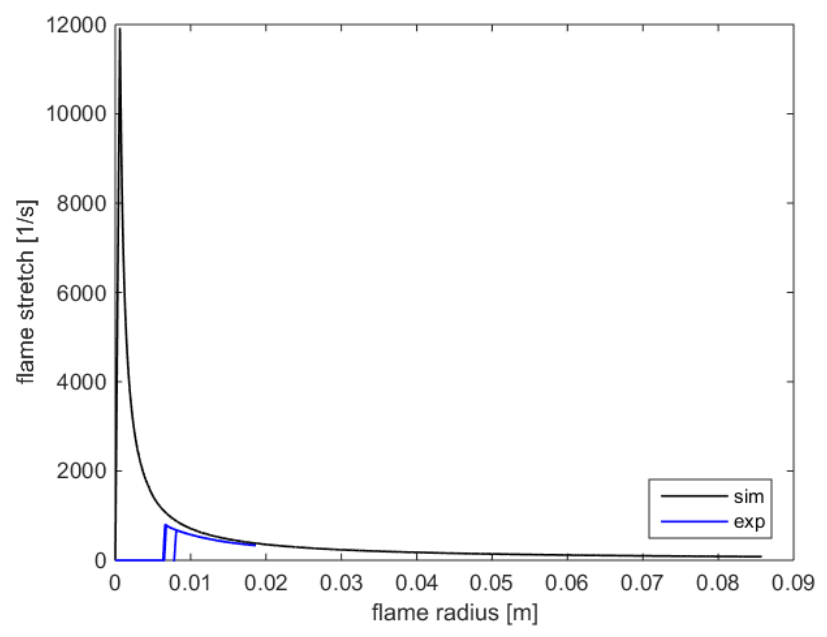

(c)

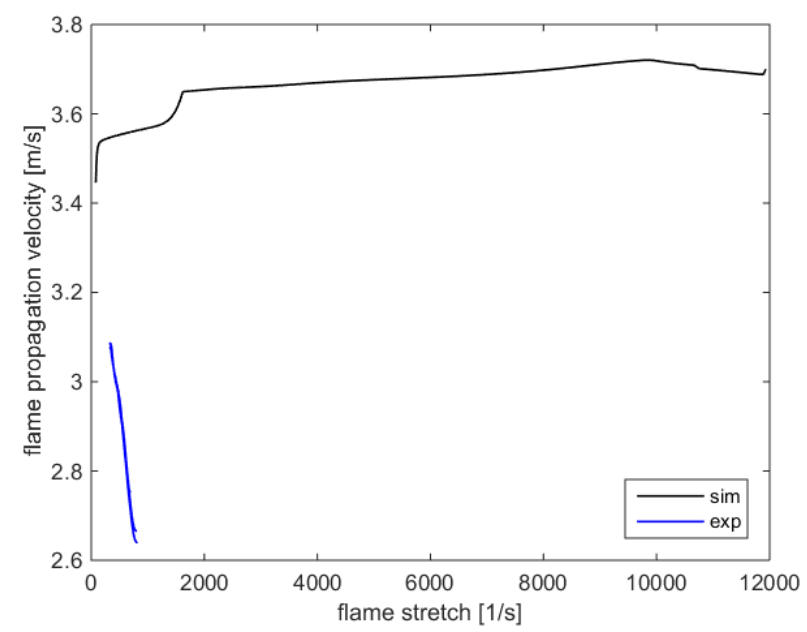

(d)

Figure 11. Evolution of: (a) flame radius as a function of the time, (b) flame velocity as a function of the time, (c) flame stretch as a function of the flame radius and (d) flame propagation velocity as a function of the flame stretch: experiments are compared to simulation. In this modeling approach, the laminar flame speed is not impacted by the flame stretch.

As shown in Figure 11 (a) and (b), by not accounting for the stretch impact on the laminar flame speed, the simulation overestimates the laminar flame speed and, accordingly, the flame radius increases faster with respect to experiments. It was possible, a posteriori, to reconstruct the flame stretch, Figure 11 (c): as shown, simulation overestimates this variable, being the flame velocity overestimated. Figure 11 (d) illustrates the fact that stretch does not have any impact on the laminar flame speed in simulation results, which is not the case for experiments. Flame speed and flame stretch mutually depend the one from the other through Equation (9) and Equation (10); by adopting a non-linear formulation, for positive Markstein lengths and very little flame radius, the propagation flame speed can reach very low values (cf. lower flame-propagation-speed branch of Figure 1 (top and bottom). As stated above, the flame speed propagation related to little flame radius is strongly impacted by the ignition process: this implies that the trajectory described by the nonlinear relation, it is not followed for those conditions. Accordingly, in this work it was necessary to fix a minimum flame radius for which the nonlinear relation becomes effective. Here, it was done the hypothesis that this radius, when dealing with positive Markstein length, corresponds to the flame radius giving the maximum flame stretch value on the nonlinear curve; this hypothesis, for given operating conditions which on the base of available database cannot be discriminated by means of the considered initial conditions, could have a non-negligible impact on the early flame development, just outside the ignition-sensitive flame-propagation region. Nevertheless, this manipulation becomes necessary from a numerical point of view for the following reasons:

- Because of the absence of an ignition model able to describe the very early flame propagation phase,

- Because of the non-one-to-one relationship between flame speed and flame stretch,

- To make the software robust enough to simulate all operating conditions.

Page 9 of 20 
No action was necessary for dealing with negative Markstein numbers, as for those conditions the flame speed increases monotonically with the flame stretch. In details, to identify the maximum-flame-stretch velocity, the maximum of the flame stretch as a function of the flame propagation speed, as described by the nonlinear relationship, was identified by mean of the following equation:

$$
\frac{d K}{d S_{b}}=-\frac{S_{b}}{L_{b} S_{b}^{0}}\left(\ln \left(\frac{S_{b}}{S_{b}^{0}}\right)^{2}+1\right)=0
$$

The value of maximum flame speed satisfying Equation (24), $S_{b_{\max }}$, is then used to retrieve the corresponding flame stretch, $K_{\max }$, by mean of Equation (10), and the corresponding flame radius, $R_{\text {min }}$, which is the one satisfying the following relation:

$$
R_{\min }=\frac{2}{K_{\max }} S_{b_{\text {max }}}
$$

Figure 12 shows, for each available experiment, that is for 166 operating conditions, the minimum radius value for which it would be possible to compute the flame propagation speed by adopting the nonlinear formulation once introduced the hypothesis formulated above.

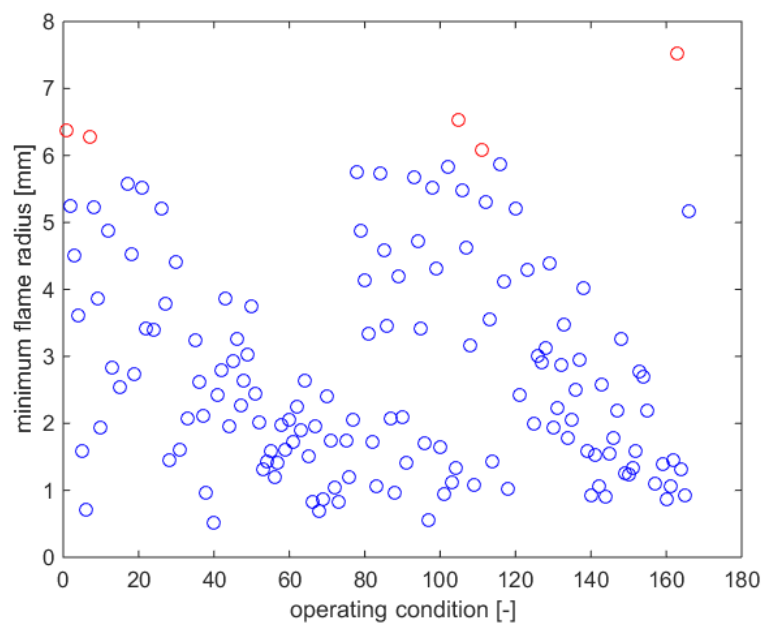

Figure 12. Minimum flame radius on the database.

As shown in Figure 12, only five operating conditions could be concerned by a bad estimation of the propagation flame-speed out of the ignition concerned flame propagation region by adopting the proposed approach; furthermore, the concerned radii remain very close to the $6 \mathrm{~mm}$ value indicated as the discriminant value between ignition-dependent and free-flame propagation regions, in [17]. This make the retained approach suitable for the present investigation work.

Figure 13 shows the simulation results, obtained by using the stretched dependent laminar flame speed approach, compared to experimental results, referring to the reference operating conditions used to generate the laminar flame speed database, the same operating conditions adopted to generate Figure 11.

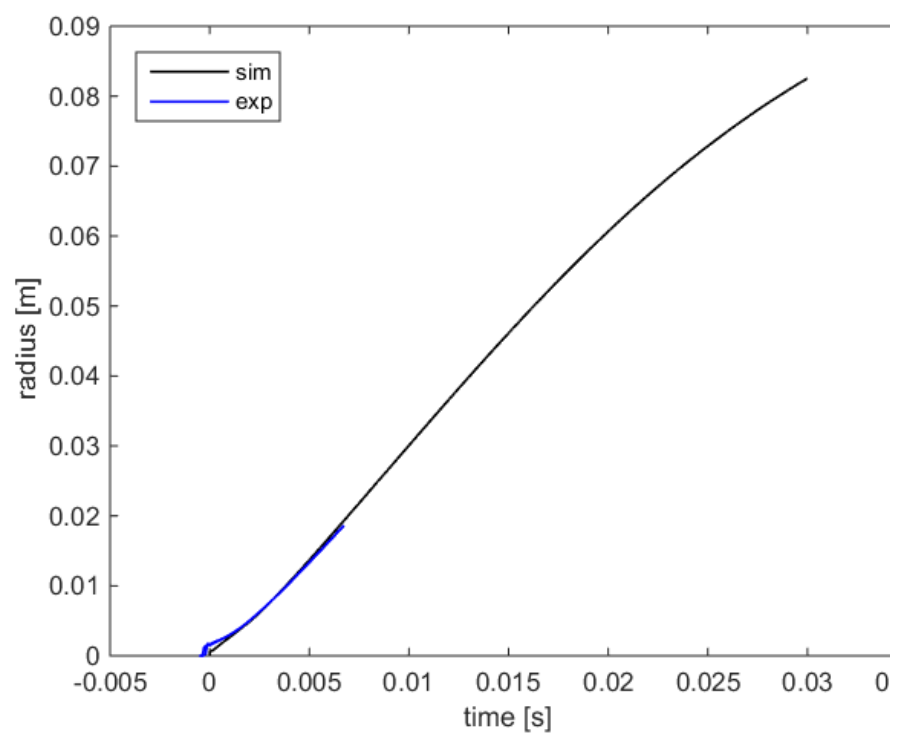

(a)

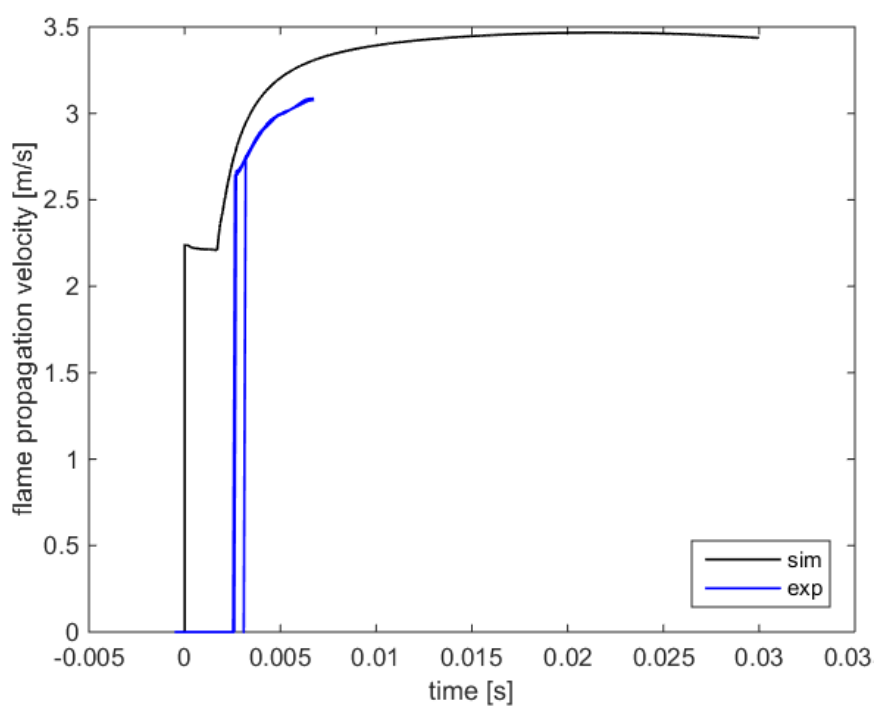

(b)

Page 10 of 20 


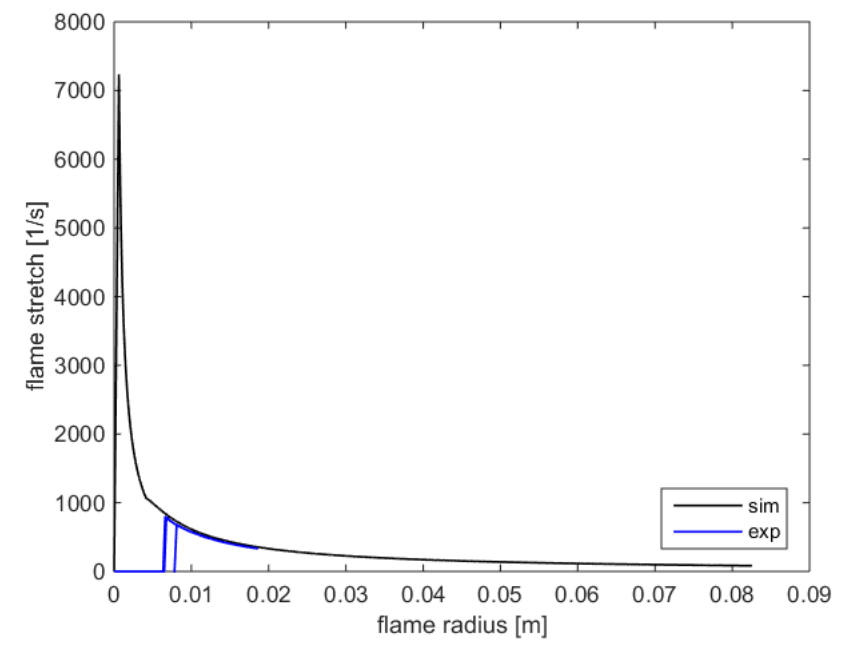

(c)

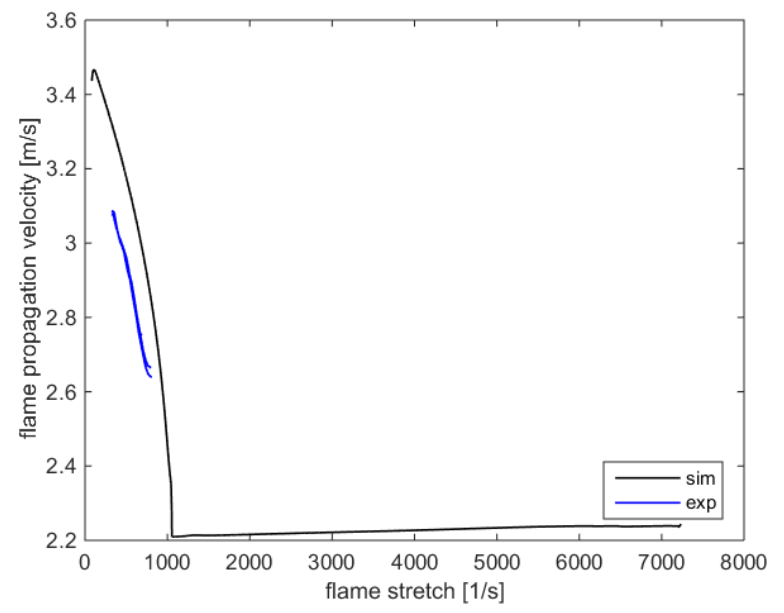

(d)

Figure 13. Evolution of: (a) flame radius as a function of the time, (b) flame velocity as a function of the time, (c) flame stretch as a function of the flame radius and (d) flame propagation velocity as a function of the flame stretch: experiments are compared to simulation. In this modeling approach, the laminar flame speed is impacted by the flame stretch.

As shown Figure 13 (a) and (b), the laminar flame speed is much better estimated and, accordingly, the evolution of the flame radius in time is more accurate and representative of the experience. It follows that, in turn, the flame stretch is better estimated, Figure 13 (c), and accordingly it is possible to retrieve the nonlinear relation between flame propagation speed and flame stretch.

\section{Laminar Flame Propagation}

In this section the simulation results relative to laminar flames will be compared to experiments. Starting from the reference condition, test condition \#0 in Table 6, single parameter variations of initial condition variables will be shown.
In this phase, no calibration parameters are available to tune simulation results to match with experiments.

Table 6. Operating conditions representative of single parametric variations around the experimental laminar reference operating condition.

\begin{tabular}{|c|c|c|c|c|}
\hline Test condition [-] & $\mathrm{T}[\mathrm{K}]$ & $\mathrm{p}[\mathrm{bar}]$ & $\phi[-]$ & Dilution rate [\%] \\
\hline$\# 0$ & 423 & 1 & 1.1 & 0 \\
$\# 1$ & $\mathbf{3 7 3}$ & 1 & 1.1 & 0 \\
$\# 2$ & 423 & $\mathbf{5}$ & 1.1 & 0 \\
$\# 3$ & 423 & $\mathbf{1 0}$ & 1.1 & 0 \\
$\# 4$ & 423 & 1 & $\mathbf{0 . 9}$ & 0 \\
$\# 5$ & 423 & 1 & $\mathbf{1 . 0}$ & 0 \\
$\# 6$ & 423 & 1 & $\mathbf{1 . 3}$ & 0 \\
$\# 7$ & 423 & 1 & 1.3 & $\mathbf{5 ~ H 2 O}$ \\
$\# 8$ & 423 & 1 & 1.3 & $\mathbf{1 0 ~ H 2 O}$ \\
$\# 9$ & 423 & 1 & 1.3 & $\mathbf{5}$ CO2 \\
$\# 10$ & 423 & 1 & 1.3 & $\mathbf{1 0 ~ C O 2}$ \\
$\# 11$ & 423 & 1 & 1.3 & $\mathbf{5 ~ E G R}$ \\
$\# 12$ & 423 & 1 & 1.3 & $\mathbf{1 0 ~ E G R}$ \\
\hline
\end{tabular}

Figure 14 to Figure 25 show the complete set of results.

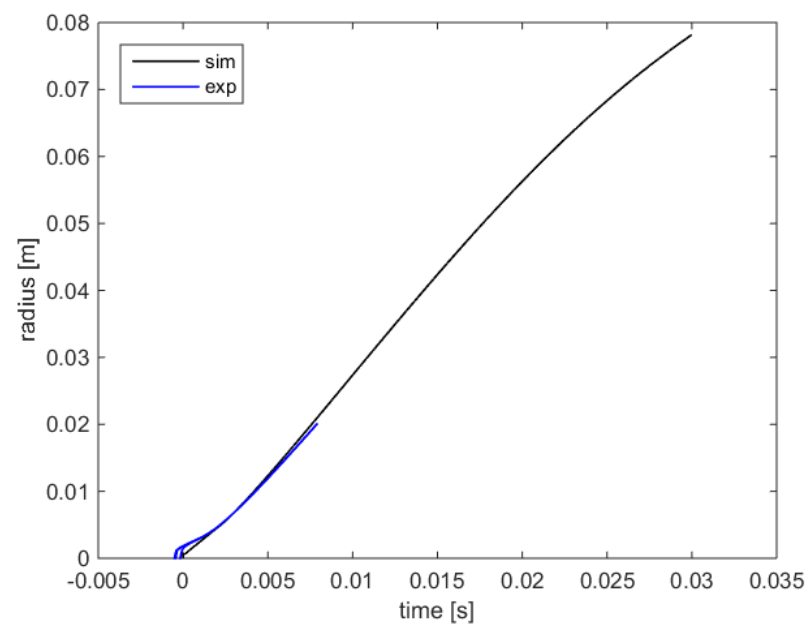

Page 11 of 20 


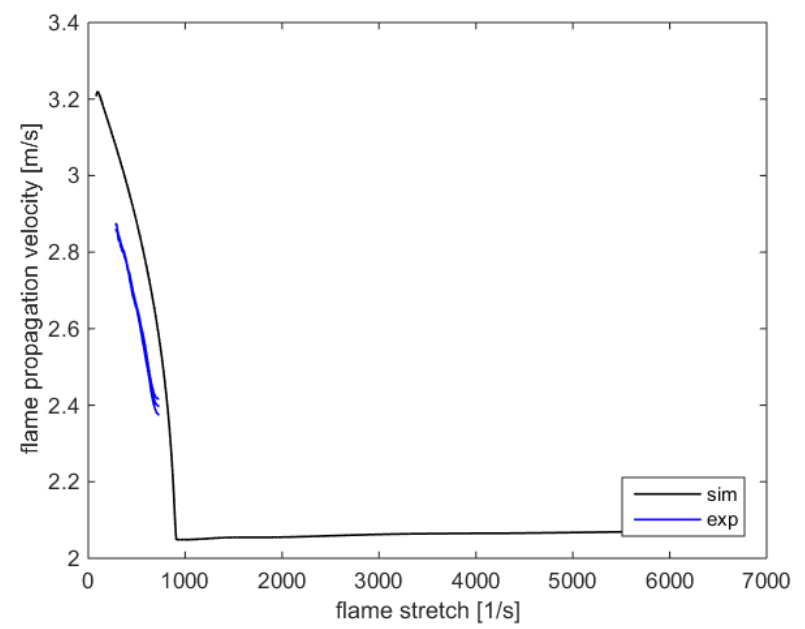

Figure 14. Comparison of simulation results with experiments, for the experimental condition relative to test condition \#1 of Table 6: evolution of the flame radius versus time (top), evolution of the flame propagation velocity versus flame stretch (bottom).
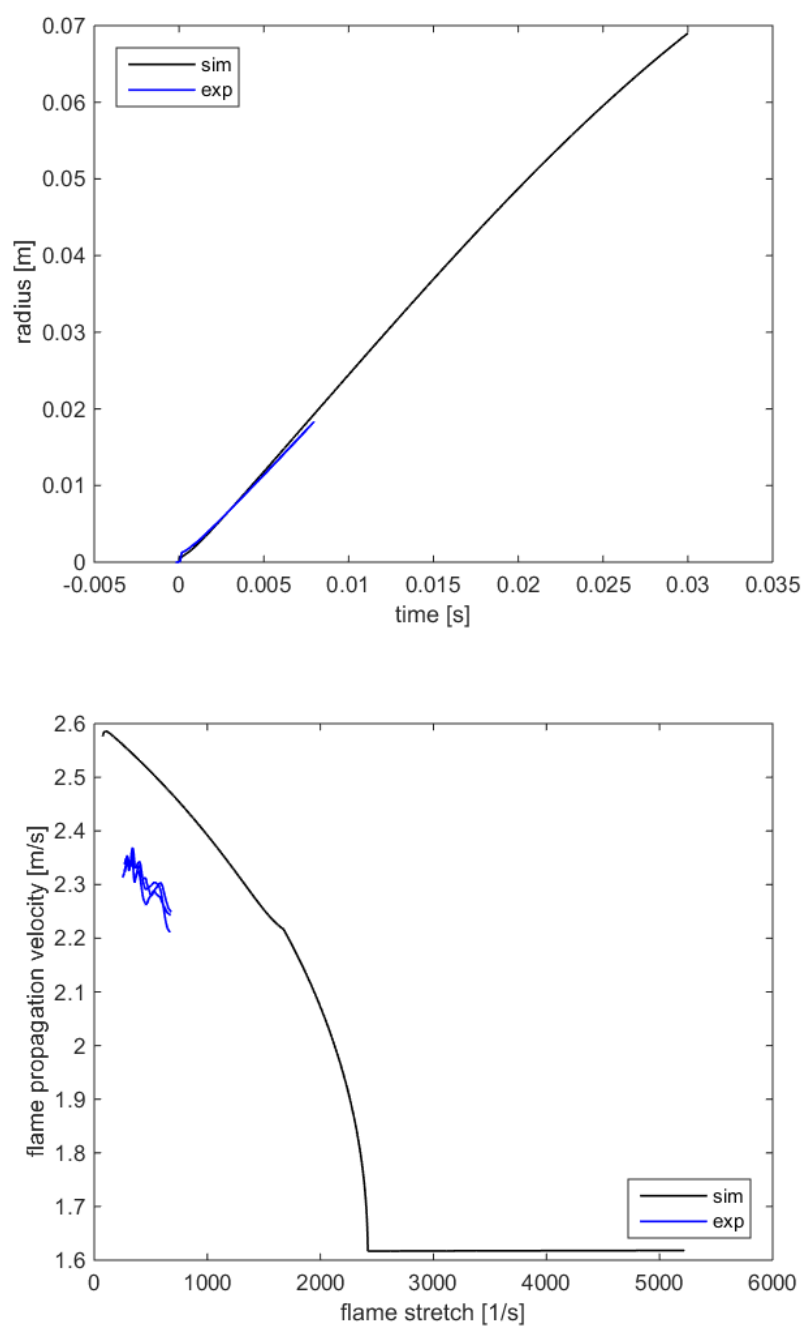

Figure 15. Comparison of simulation results with experiments, for the experimental condition relative to test condition \#2 of Table 6: evolution of

Page 12 of 20 the flame radius versus time (top), evolution of the flame propagation velocity versus flame stretch (bottom).
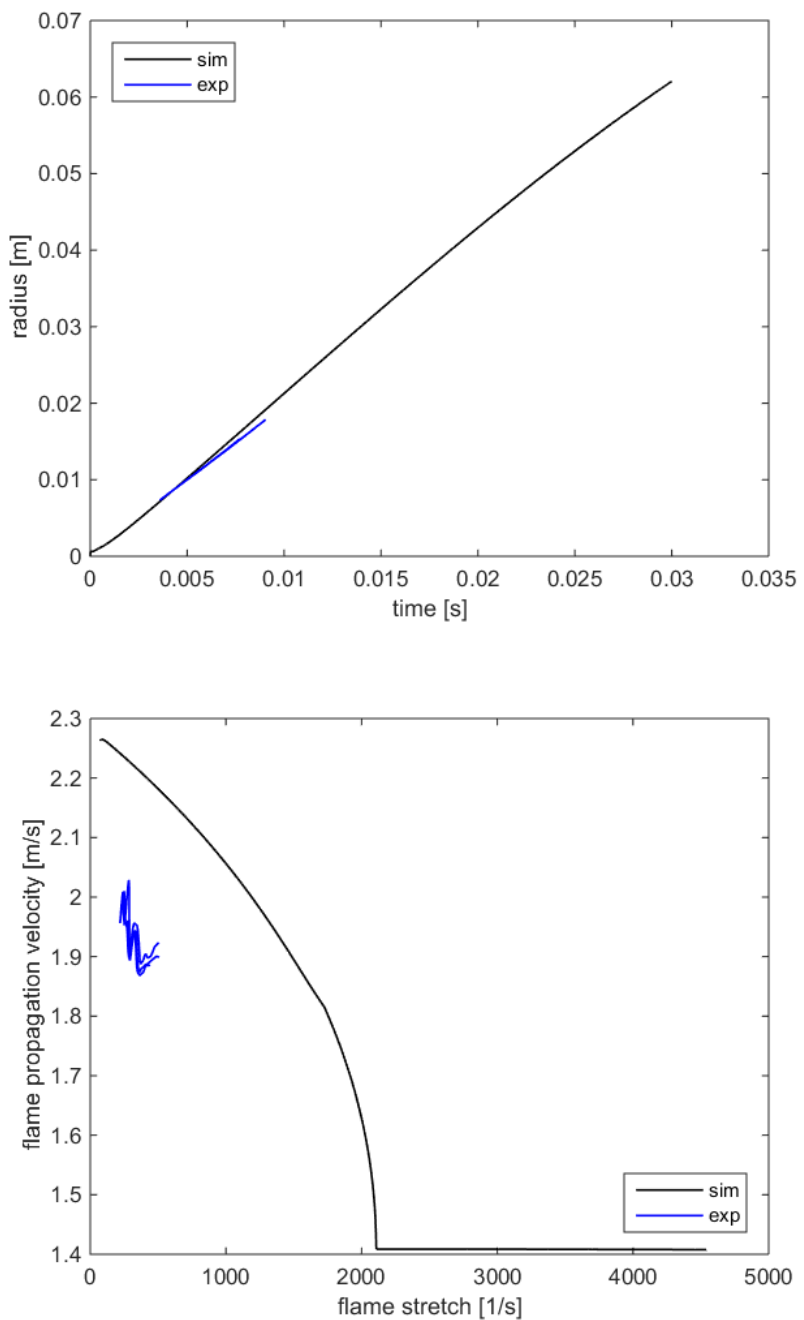

Figure 16. Comparison of simulation results with experiments, for the experimental condition relative to test condition \#3 of Table 6: evolution of the flame radius versus time (top), evolution of the flame propagation velocity versus flame stretch (bottom). 

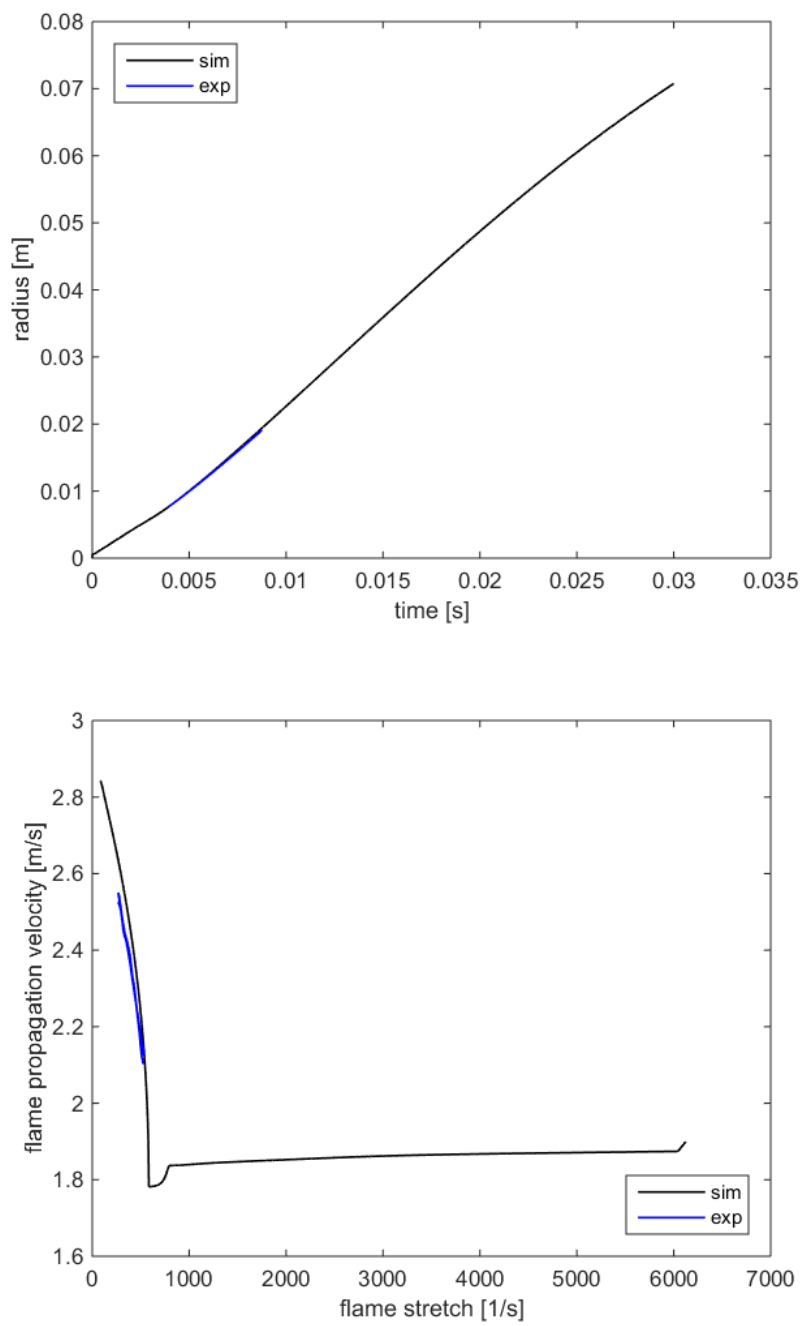

Figure 17. Comparison of simulation results with experiments, for the experimental condition relative to test condition \#4 of Table 6: evolution of the flame radius versus time (top), evolution of the flame propagation velocity versus flame stretch (bottom).

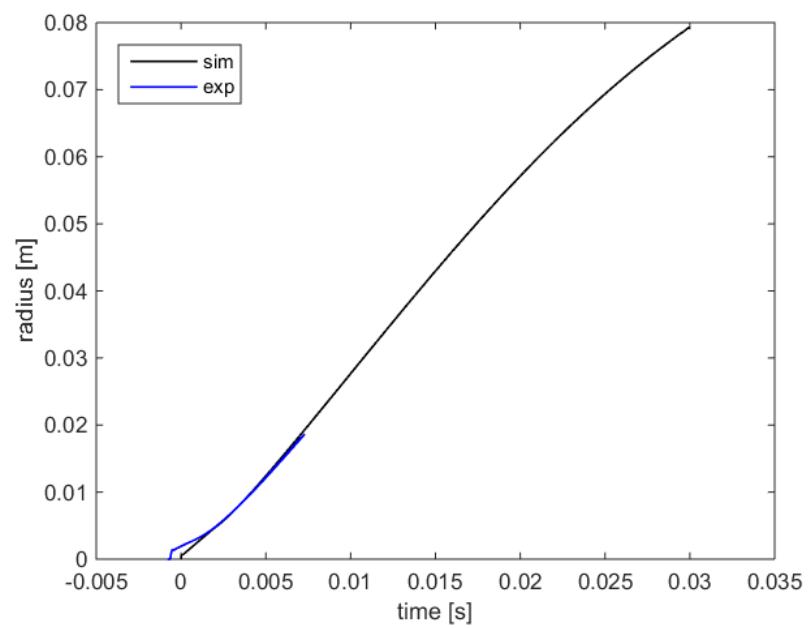

Page 13 of 20

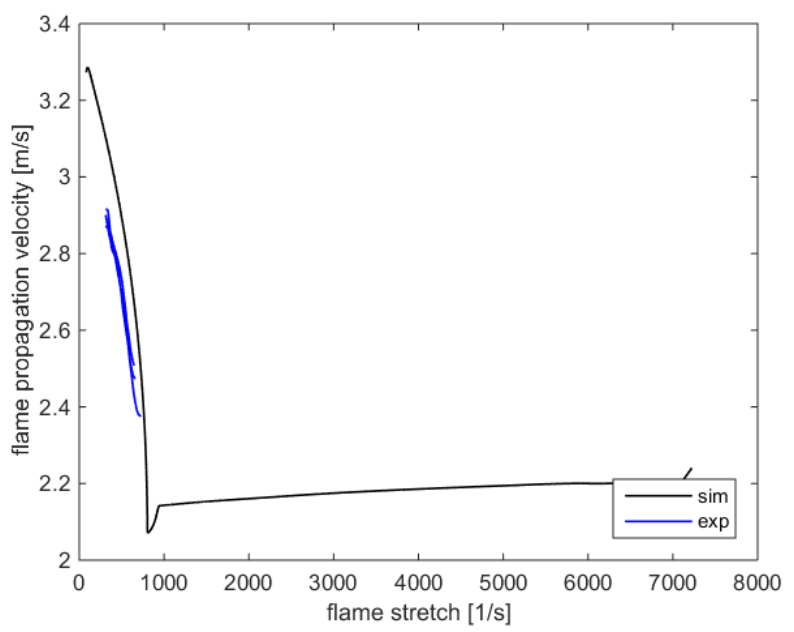

Figure 18. Comparison of simulation results with experiments, for the experimental condition relative to test condition \#5 of Table 6: evolution of the flame radius versus time (top), evolution of the flame propagation velocity versus flame stretch (bottom).
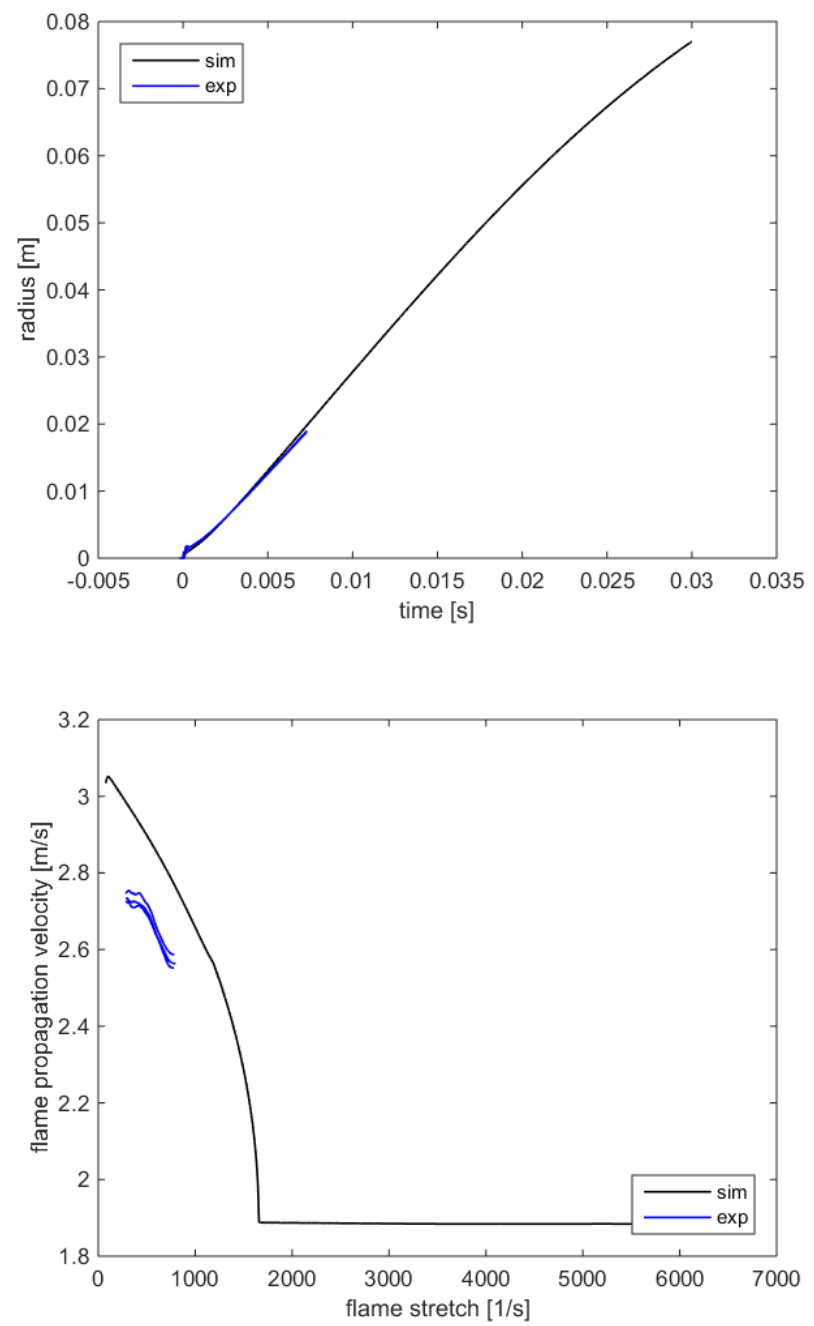

Figure 19. Comparison of simulation results with experiments, for the experimental condition relative to test condition \#6 of Table 6: evolution of 
the flame radius versus time (top), evolution of the flame propagation velocity versus flame stretch (bottom)
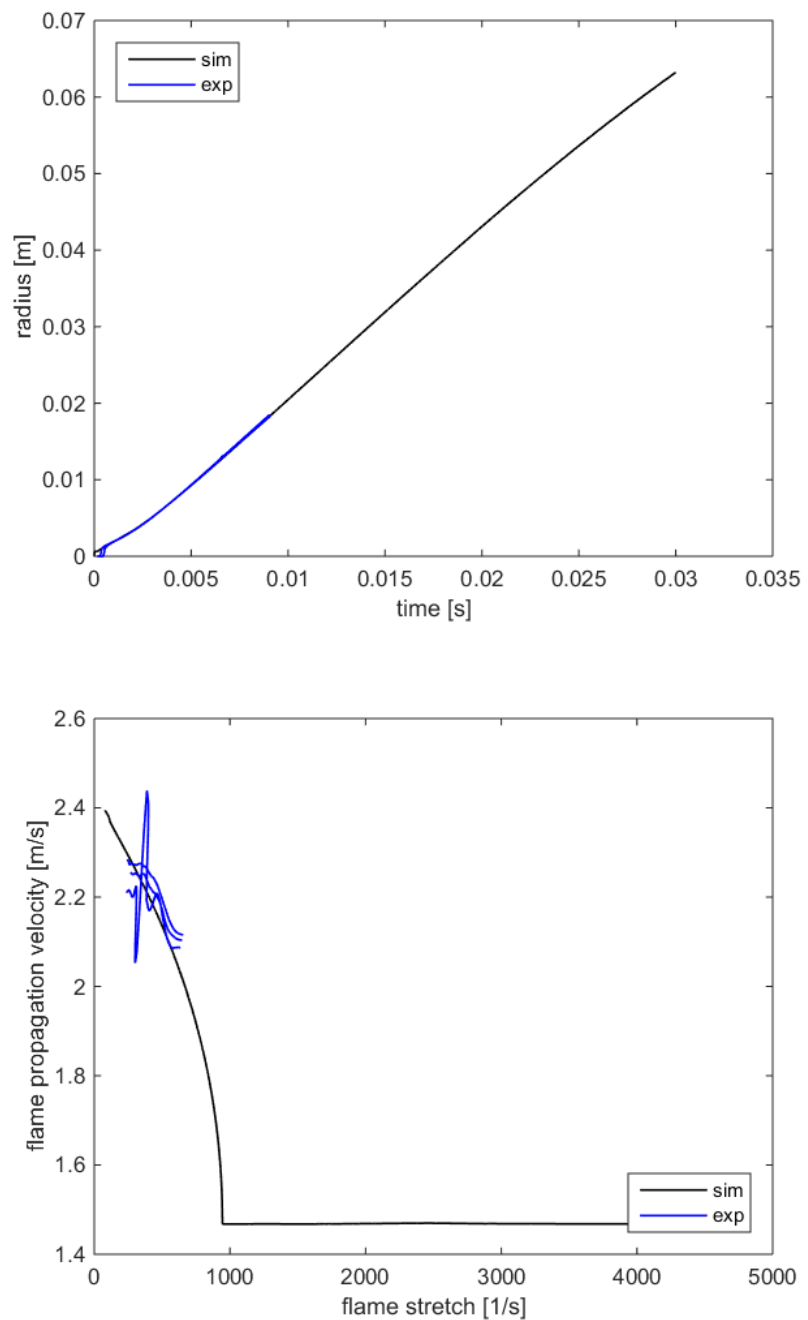

Figure 20. Comparison of simulation results with experiments, for the experimental condition relative to test condition \#7 of Table 6: evolution of the flame radius versus time (top), evolution of the flame propagation velocity versus flame stretch (bottom).
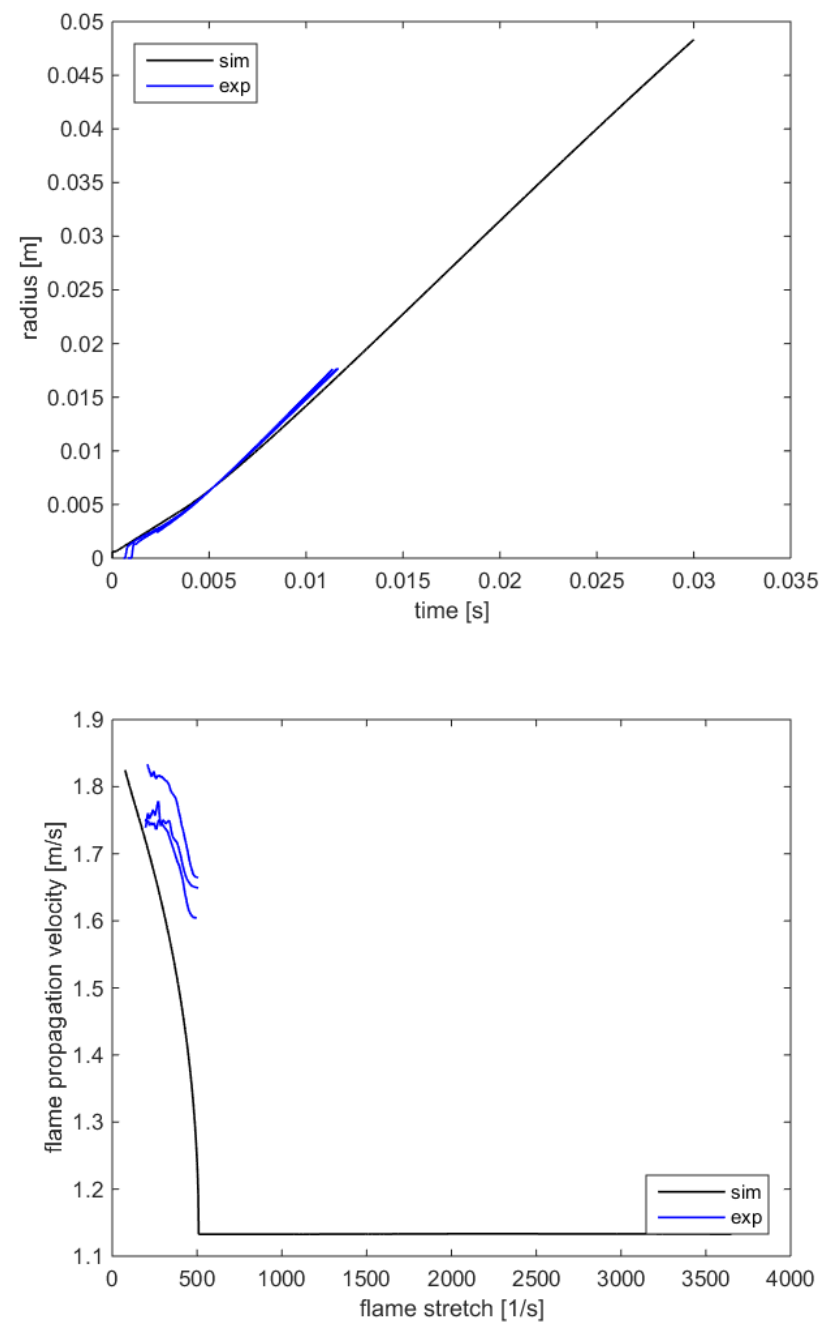

Figure 21. Comparison of simulation results with experiments, for the experimental condition relative to test condition \#8 of Table 6: evolution of the flame radius versus time (top), evolution of the flame propagation velocity versus flame stretch (bottom).

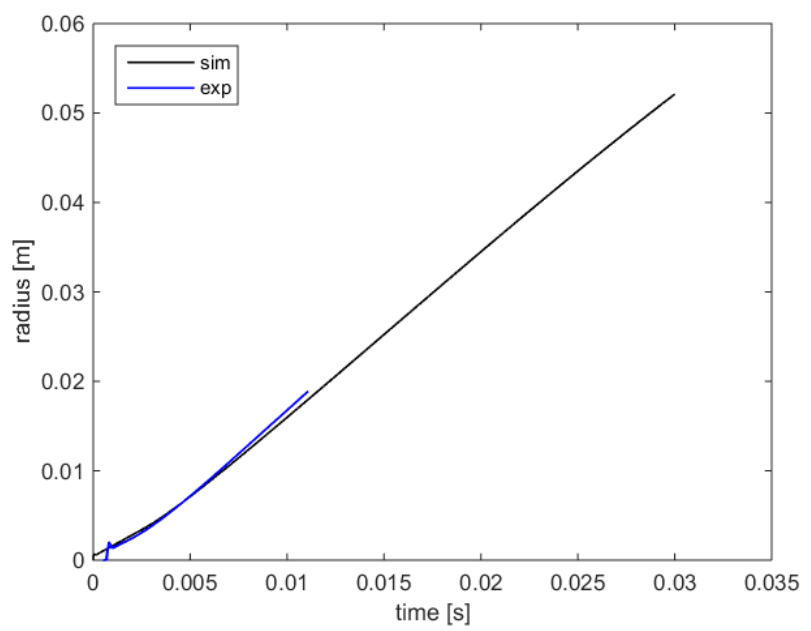

Page 14 of 20 


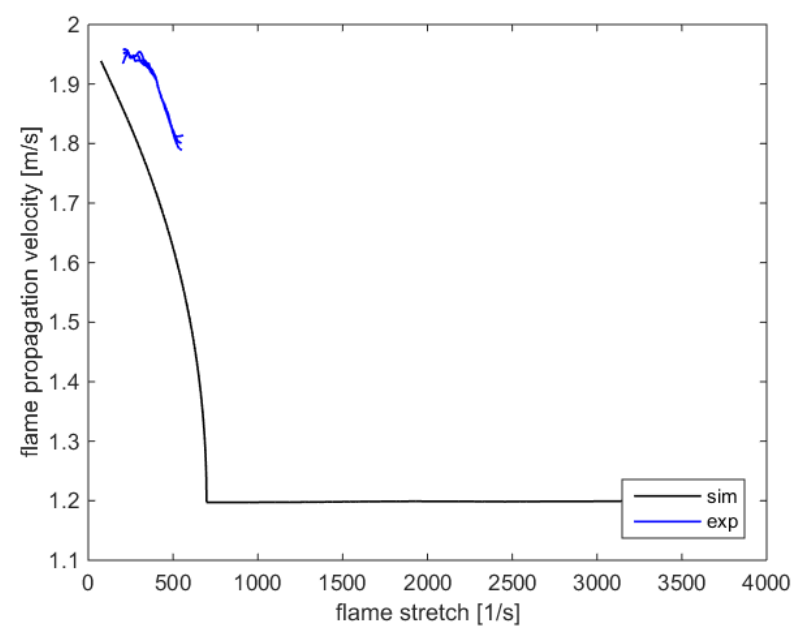

Figure 22. Comparison of simulation results with experiments, for the experimental condition relative to test condition \#9 of Table 6: evolution of the flame radius versus time (top), evolution of the flame propagation velocity versus flame stretch (bottom).
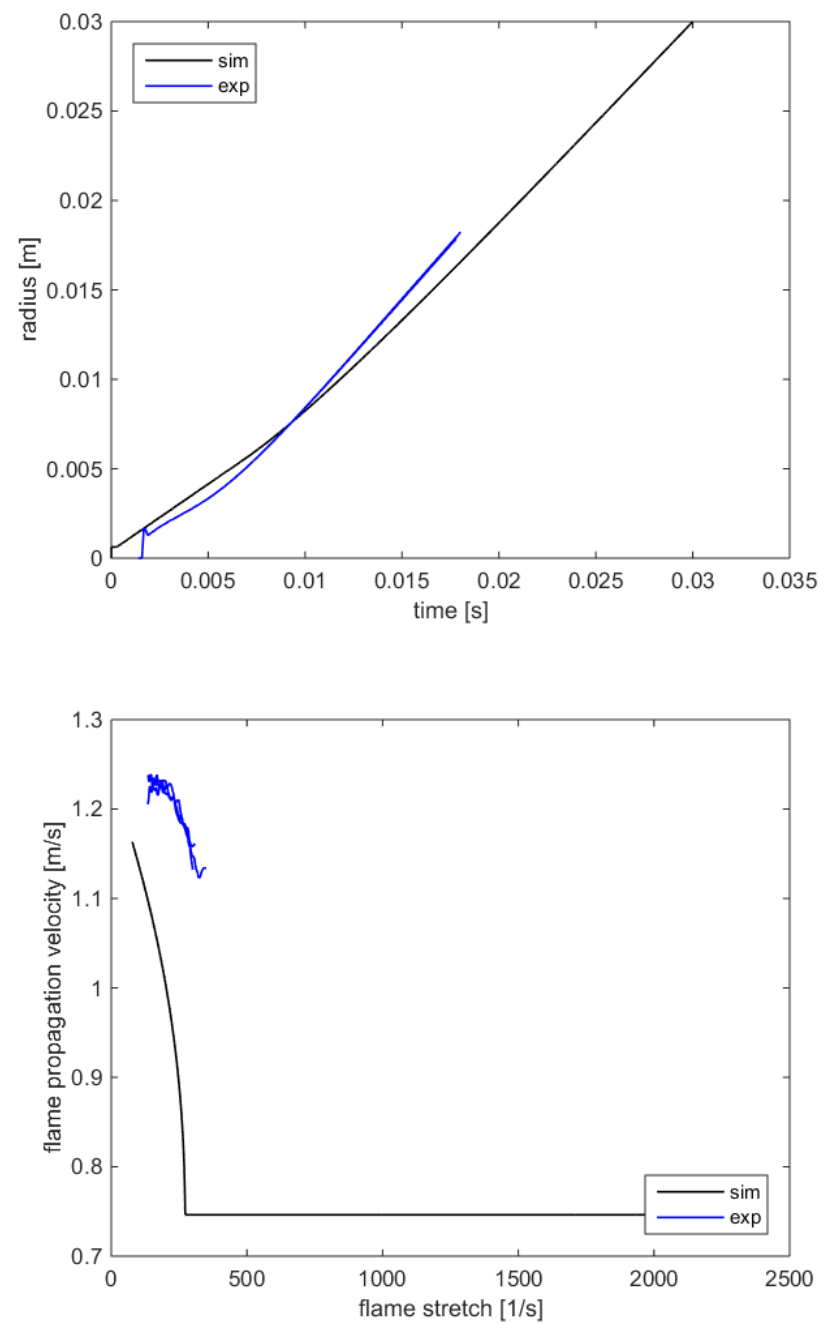

Figure 23. Comparison of simulation results with experiments, for the experimental condition relative to test condition \#10 of Table 6: evolution of

\section{Page 15 of 20}

the flame radius versus time (top), evolution of the flame propagation velocity versus flame stretch (bottom).
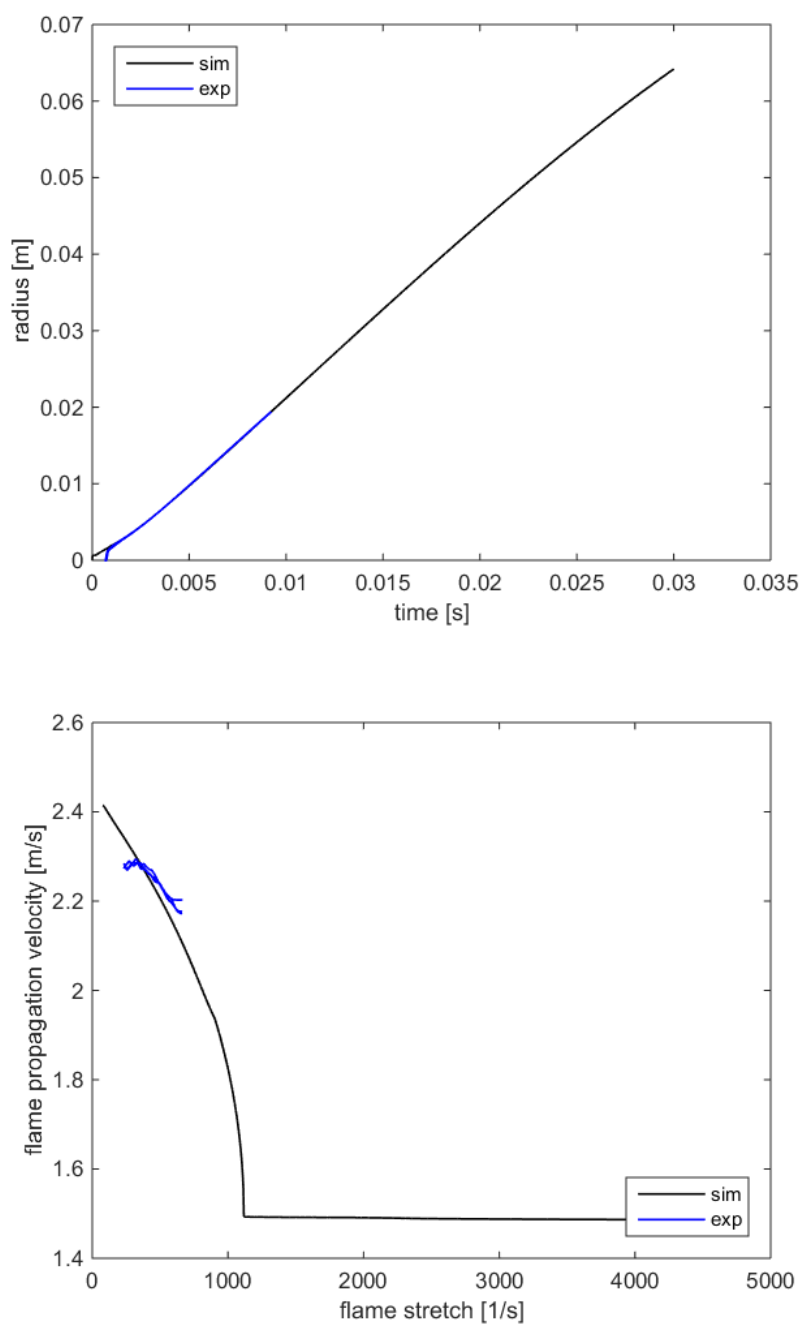

Figure 24. Comparison of simulation results with experiments, for the experimental condition relative to test condition \#11 of Table 6: evolution of the flame radius versus time (top), evolution of the flame propagation velocity versus flame stretch (bottom). 

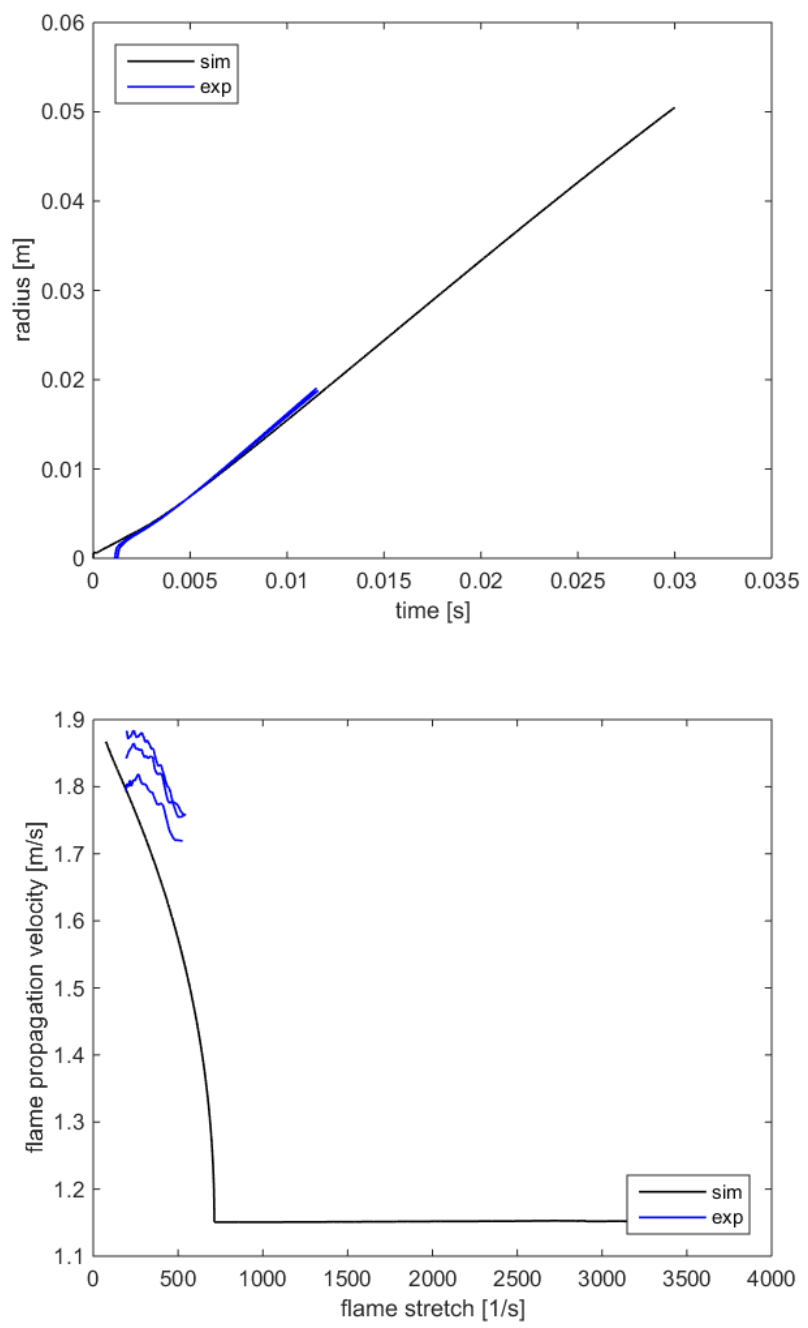

Figure 25. Comparison of simulation results with experiments, for the experimental condition relative to test condition \#12 of Table 6: evolution of the flame radius versus time (top), evolution of the flame propagation velocity versus flame stretch (bottom)

As shown in Figure 14 to Figure 25, the model fairly represents variation of temperature, pressure, equivalence ratio, and dilution rates of $\mathrm{H} 2 \mathrm{O}, \mathrm{CO} 2$ and synthetic stoichiometric EGR; nevertheless, it was observed that for high values of dilution rates, higher than $15 \%$, the model begin to underestimate the flame propagation speed. This is possibly due to the fact at high equivalence ratios and in presence of diluent, the burned gas composition computed by the model, which accounts for a limited number of gases (fuel, O2, N2, CO2, CO, $\mathrm{H} 2 \mathrm{O}, \mathrm{H} 2, \mathrm{NO}, \mathrm{NO} 2$ ) is not as accurate as it should be to be representative of the reality.

\section{Turbulent Flame Propagation}

Two calibration parameters are available to tune the CFM1D simulation results to match experiments; the parameters:

- $\alpha$, gain on the turbulent strain rate related to turbulence/flame interaction given by the efficiency function proposed in [47],
- $\mathrm{k}_{\mathrm{wrink}}$, gain acting on the flame wrinkling derivative allowing to calibrate the transient phase of adaptation of the flame front to the turbulence field, [46].

For the sake of clarity it is worth to remind that experiments were conducted under mastered turbulent flow conditions for which the characteristics of turbulence were known [19]; accordingly, no calibration parameters were available to act on turbulence, which was considered as an experiment boundary condition. After the calibration of the two parameters, aiming to minimize the errors between simulation results and experiments, the parameterization of the model was kept unchanged for all the simulations. The retained values of the calibration parameters are given in Table 7 .

Table 7. Operating conditions representative of single parametric variations around the experimental reference operating condition.

\begin{tabular}{|c|c|c|}
\hline Calibration parameter & Unit & Value \\
\hline$\alpha$ & - & 0.8 \\
$\mathrm{k}_{\text {wrink }}$ & - & 0.9 \\
\hline
\end{tabular}

The calibration parameters mainly acting on the turbulence/flame interaction, particular attention was paid during the calibration process to be representative of variations of the turbulent flow field, that is to variations of the turbulent intensity. The simulation results relative to turbulent flames will be compared to experiments. Starting from the reference condition, test \#0 in Table 8, single parameter variations of initial conditions were performed.

Table 8. Operating conditions representative of single parametric variations around the experimental turbulent reference operating condition.

\begin{tabular}{|c|c|c|c|c|c|}
\hline $\begin{array}{c}\text { Test condition } \\
{[-]}\end{array}$ & $\begin{array}{c}\mathrm{T} \\
{[\mathrm{K}]}\end{array}$ & $\begin{array}{c}\mathrm{p} \\
{[\mathrm{b} a r]}\end{array}$ & $\phi[-]$ & $\begin{array}{c}\text { Dilution rate } \\
{[\%]}\end{array}$ & $\begin{array}{c}\mathrm{u}^{\prime} \\
{[\mathrm{m} / \mathrm{s}]}\end{array}$ \\
\hline$\# 0$ & 423 & 1 & 1.0 & 0 & 1.39 \\
$\# 1$ & 423 & 1 & 1.0 & 0 & $\mathbf{0 . 6 9}$ \\
$\# 2$ & 423 & 1 & 1.0 & 0 & $\mathbf{2 . 4 3}$ \\
\hline
\end{tabular}

Figure 26 to Figure 28 show the complete set of results.

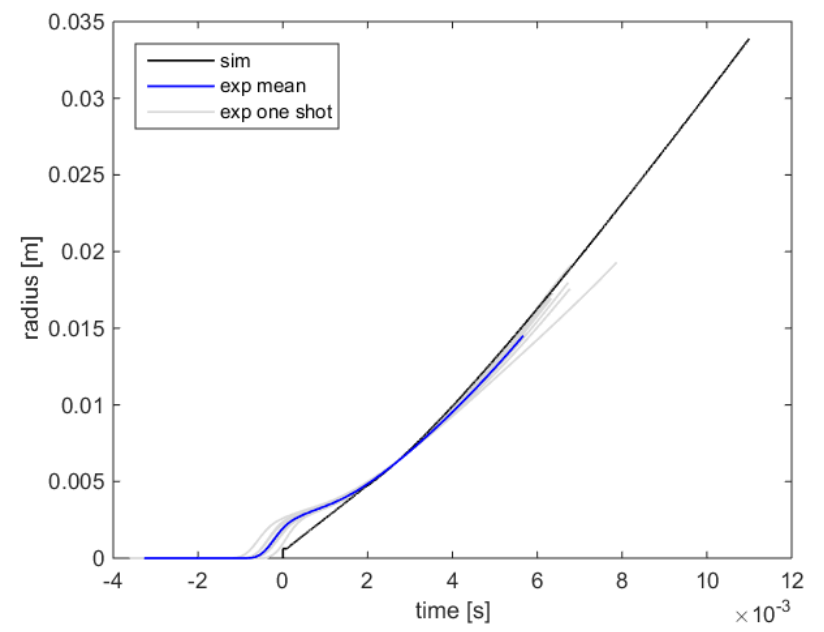

Page 16 of 20 


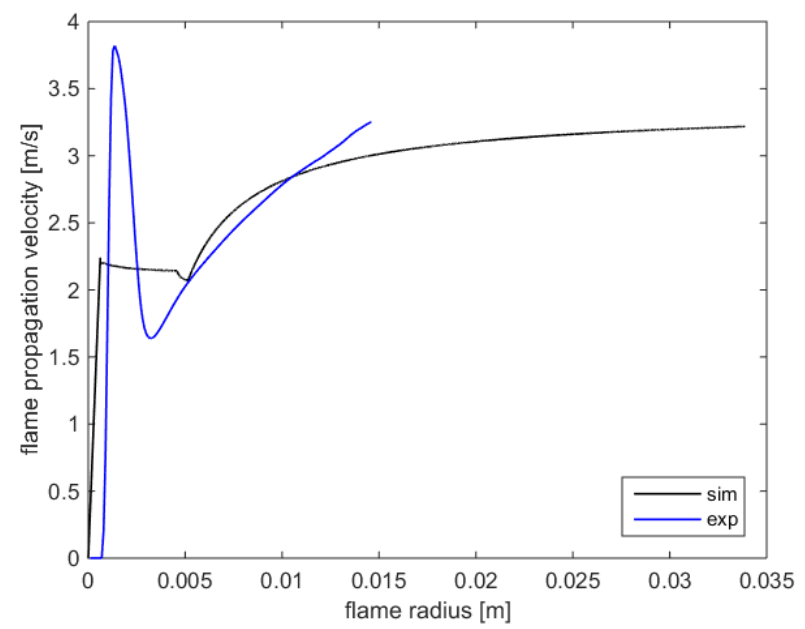

Figure 26. Comparison of simulation results with experiments, for the experimental condition relative to test condition $\# 0$ of Table 8: evolution of the flame radius versus time (top), evolution of the flame propagation velocity versus flame radius (bottom).
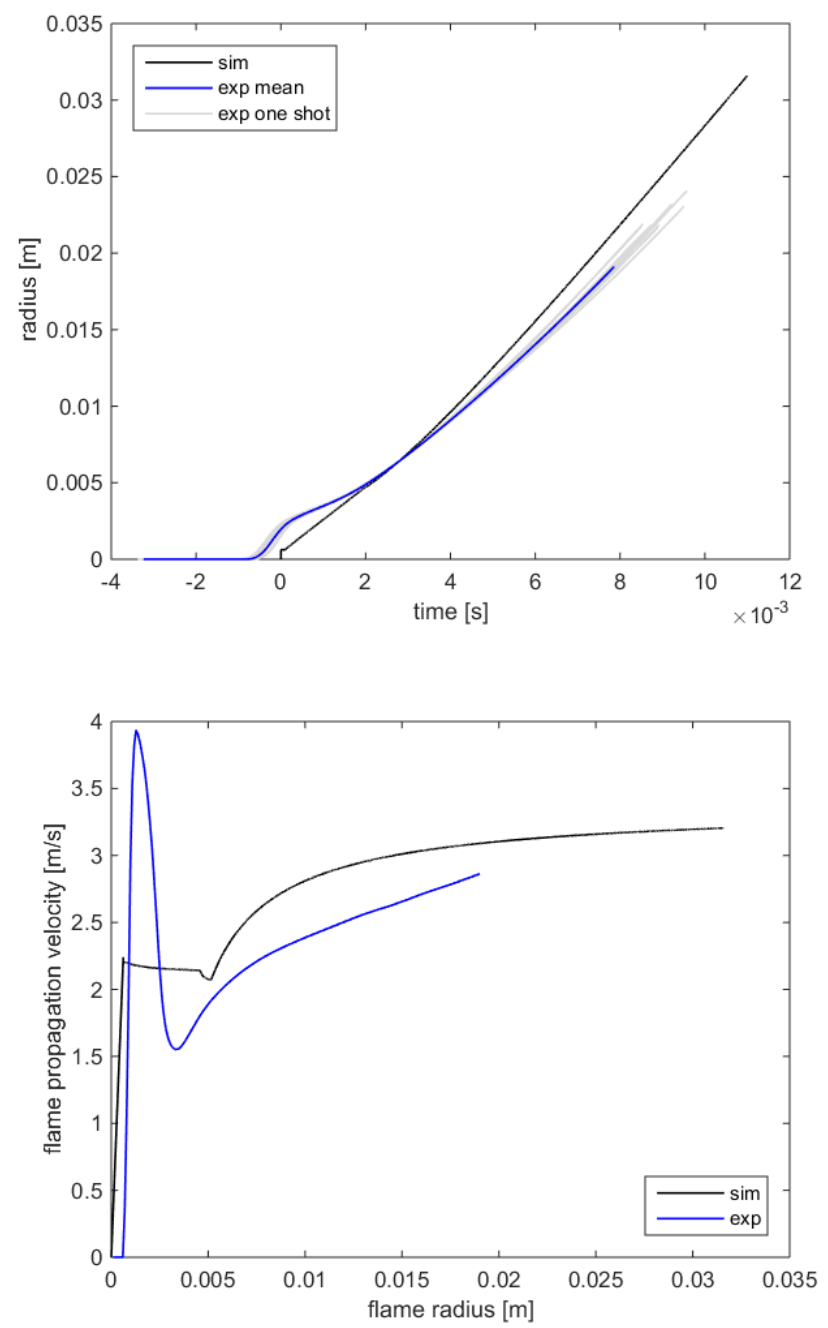

Figure 27. Comparison of simulation results with experiments, for the experimental condition relative to test condition \#1 of Table 8: evolution of the flame radius versus time (top), evolution of the flame propagation velocity versus flame radius (bottom)
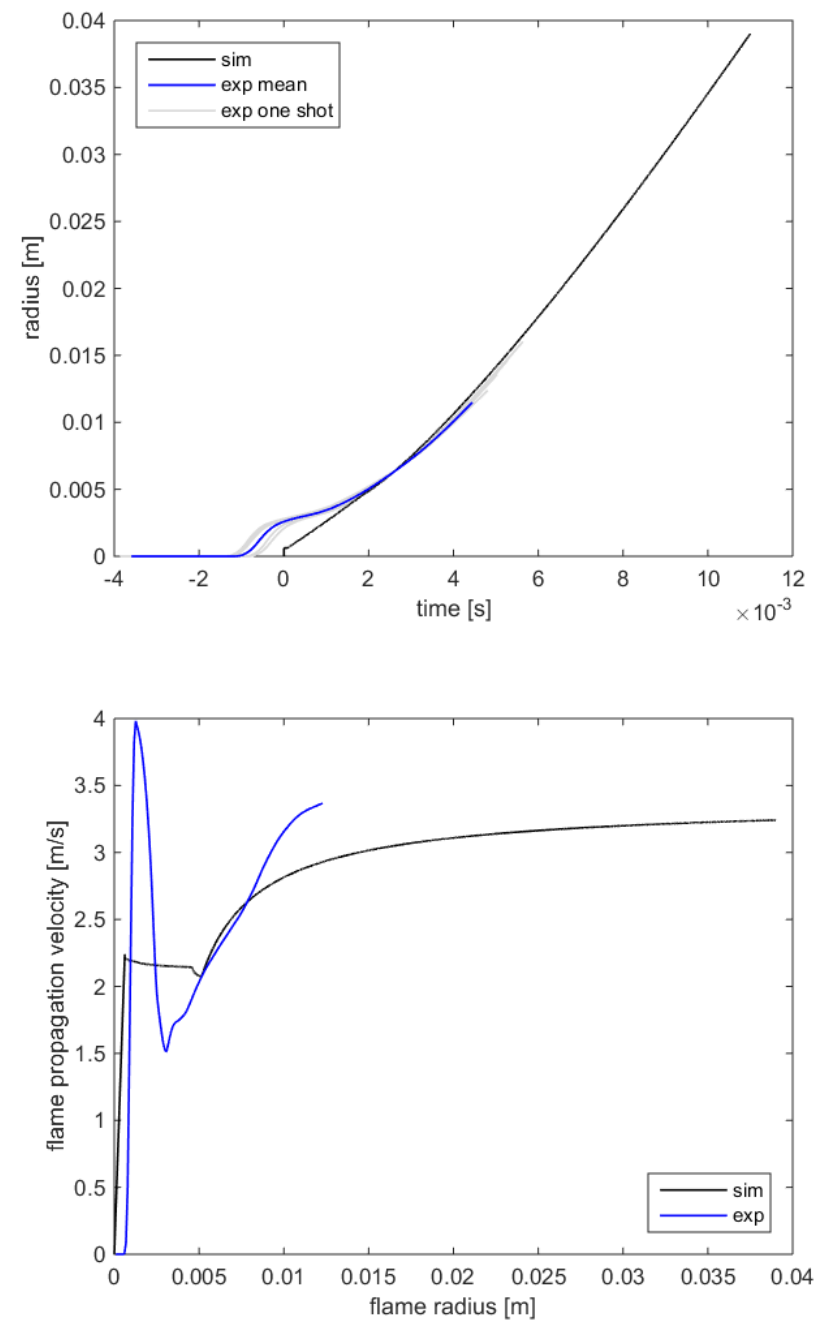

Figure 28. Comparison of simulation results with experiments, for the experimental condition relative to test condition \#2 of Table 8: evolution of the flame radius versus time (top), evolution of the flame propagation velocity versus flame radius (bottom).

As shown in Figure 26 to Figure 28, the model fairly represents variations of turbulent intensity.

\section{Conclusion}

In this study a premixed combustion model able to give a reliable representation of the effective laminar flame speed accounting for flame stretch impact, dilution and dilution composition (in the specific, $\mathrm{O} 2, \mathrm{H} 2 \mathrm{O}, \mathrm{CO} 2$ and synthetic stoichiometric EGR $(\mathrm{CO} 2+\mathrm{H} 2 \mathrm{O}+\mathrm{N} 2))$ was developed and integrated into the 0D CFM combustion model, available in the IFP-Engine library of the multiphysics simulation platform Simcenter Amesim software, the CFM1D. For this, the experimental databases generated at the PRISME laboratory referring to laminar and turbulent flames propagating in a closed vessel at different initial thermo-chemical conditions were used to extract valuable information and validate the model performance.

Page 17 of 20 
In a first time, the model was validated by mean of the experimental database relative to laminar expanding spherical flames taking place in a closed constant volume vessel. Globally it was possible to retrieve numerically the qualitative and quantitative physical behavior of the flame, as a function of the initial conditions of the reactive mixture. Nevertheless, it was observed that some discrepancies appeared for high values of ambient pressure and high values of dilution rate. The reasons of these discrepancies were possibly associated to the fact that the phenomenological correlations for the laminar flame speed and the Markstein number, developed on the base of the experimental data, apply to a more reduced domain, and to the fact that in simulation the burned gas composition is described by a reduced number of chemical species, while in reality, much more species are required to accurately describe it, especially for complex-fuels, rich and diluted combustions. In a second time, the model was validated by mean of the experimental database relative to turbulent expanding spherical flames taking place in a closed constant volume vessel. Once again, globally, it was possible to retrieve numerically the qualitative and quantitative physical behavior of the flame, as a function of the initial conditions of the turbulent reactive mixture.

\section{References}

1. H. Adelman. A time dependent theory of spark ignition. In 18th Symp. (Int.) on Combust., pages 1333-1342. The Combustion Institute, 1981.

2. R.J. Blint. The relationship of the laminar flame width to flame speed. Combustion Science and Technology, 49:79-92, 1986.

3. A. Bonhomme, L. Selle, and T. Poinsot. Curvature and confinement effects for flame speed measurements in laminar spherical and cylindrical flames. Combust. Flame, 160:12081214, 2013.

4. H. Boughanem. Evaluation des termes de transport et de dissipation de surface de flamme par simulation numérique directe de la combustion turbulente, Thèse de doctorat. PhD thesis, Institut Français du Pétrole, France, 1998.

5. R. Bounaceur, O. Herbinet, R. Fournet, P.-A. Glaude, F. BattinLeclerc, A. Pires da Cruz, M. yahyaoui, K. Truffin, and G. Moreac. Modeling the Laminar Flame Speed of Natural Gas and Gasoline Surrogates. SAE Technical Paper 2010-01-0546, pages 1-16, 2010.

6. D. Bradley and A.Mitcheson. Mathematical solutions for explosions in spherical vessels. Combust. Flame, 26:201-217, 1976.

7. D. Bradley, P. Gaskell, X. Gu, and A . Sedaghat. Premixed flamelet modeling: factors influencing the turbulent heat release rate source term and the turbulent burning velocity. Combust. Flame, 143:227-245, 2005.

8. D. Bradley, R A Hicks, M Lawes, C G W Sheppard, and R Woolley. The Measurement of Laminar Burning Velocities and Markstein Numbers for Isooctane / Air and Isooctane/ nHeptane / Air Mixtures at Elevated Temperatures and Pressures in an Explosion Bomb. Combust. Flame, 144:126-144, 1998.

9. D. Bradley, M. Lawes, K. Liu, and M.S. Mansour. Measurements and correlations of turbulent burning velocities over wide ranges of fuels and elevated pressures. Proc. Combust. Inst., 34(1):1519-1526, 2013.

10. G. Broustail, P. Seers, F. Halter, G. Moreac, and C. MounaimRousselle. Experimental determination of laminar burning velocity for butanol and ethanol isooctane blends. Fuel, 90(1):16, January 2011.

Page 18 of 20
11. S.M. Candel and T. Poinsot. Flame stretch and the balance equation for the flame surface area. Combust. Sci. and Tech., 70:1-15, 1990.

12. O. Colin, F. Ducros, D. Veynante, and T. Poinsot. A thickened flame model for large eddy simulations of turbulent premixed combustion. Physics of Fluids, 12(7):1843-1863, 2000.

13. O. Colin and K. Truffin. A spark ignition model for large eddy simulation based on an FSD transport equation (ISSIM-LES). Proc. Combust. Inst., 33(2):3097 - 3104, 2011.

14. Olivier Colin and Michael Rudgyard. Development of highorder Taylor-Galerkin schemes for LES. J. Comput. Phys., 162(2):338-371, 2000.

15. J. M. Duclos and O. Colin. Arc and kernel tracking ignition model for 3D spark ignition engine calculations. In COMODIA, pages 343-350, Nagoya, Japon, 2001.

16. J.T. Farrel, R.J. Johnston, and I.P. Androulakis. Molecular Structure Effects On Laminar Burning Velocities At Elevated Temperature And Pressure. SAE Paper 2004-01-2936, 2004.

17. B. Galmiche. Caracterisation experimentale des flammes laminaires et turbulentes en expansion. $\mathrm{PhD}$ thesis, Universite d'Orleans, 2014.

18. B. Galmiche, F. Halter, and F. Foucher. Effects of high pressure, high temperature and dilution on laminar burning velocities and Markstein lengths of isooctane/air mixtures. Combust. Flame, 159:3286-3299, 2012.

19. B. Galmiche, N. Mazellier, F. Halter, and F. Foucher. Turbulence characterization of a high-pressure high-temperature fan-stirred combustion vessel using LDV, PIV and TR-PIV measurements. Experiments in Fluids, 55:1636, 2014.

20. J.O. Hinze. Turbulence. McGraw-Hill, mcgraw-hill classic textbook reissue edition, 1987.

21. S. Jerzembeck, N. Peters, P. Pepiot-Desjardins, and H. Pitsch. Laminar burning velocities at high pressure for primary reference fuels and gasoline: Experimental and numerical investigation. Combust. Flame, 156(2):292 - 301, 2009.

22. G. Tabor A. Gosman N. Lawes C. Sheppard R. Wooley K. Nwagwe, H. Weller. and large eddy simulations of turbulent premixed flame kernel growth. Proc. Combust. Inst., 28(1):59$65,2000$.

23. A.P. Kelley and C.K. Law. Non linear effects in the extraction of laminar flame speeds From expanding spherical flames. Combust. Flame, 156(9):1844-1851, 2009.

24. A.P. Kelley, A.J. Smallbone, D.L. Zhu, and C.K. Law. Laminar flame speeds of $\mathrm{C} 5$ to $\mathrm{C} 8 \mathrm{n}$-alkanes at elevated pressures: Experimental determination, fuel similarity, and stretch sensitivity. Proc. Combust. Inst.,, 33:963-970, 2011.

25. S. Kwon, M.-S. Wu, J.F. Driscoll, and G.M. Faeth. Flame surface properties of premixed flames in isotropic turbulence: Measurements and numerical simulations. Combust. Flame, 88(2):221-238, February 1992.

26. M. Metghalchi and J.C. Keck. Laminar burning velocity of propane-air mixtures at high temperature and pressure. Combust. Flame, 38:143-154, 1980.

27. D.M. Mosbacher, J.A. Wehrmeyer, R.W. Pitz, C.J. Sung, and J.L. Byrd. Experimental and numerical investigation of premixed tubular flames. Proc. Combust. Inst., 29(2):14791486, 2002.

28. F. Nicoud, H. Baya Toda, O. Cabrit, S.T. Bose, and J. Lee. Using singular values to build a subgrid-scale model for large eddy simulations. Physics of Fluids, 23:085-106, 2011.

29. T. Passot and A. Pouquet. Numerical simulation of compressible homogeneous flows in the turbulent regime. Journal of Fluid Mechanics, 181:441 - 466, 1987.

30. T. Poinsot and D. Veynante. Theoretical and numerical combustion. T. Poinsot, 2011. 
31. T. J. Poinsot and S. K. Lele. Boundary conditions for direct simulations of compressible viscous flows. J. Comput. Phys., 101(1):104 - 129, 1992.

32. S. Richard. Simulation aux grandes échelles de la combustion dans les moteurs à allumage commandé. $\mathrm{PhD}$ thesis, Ecole Centrale Paris, 2005.

33. S. Richard, O. Colin, O. Vermorel, A. Benkenida, C. Angelberger and D. Veynante. Towards large eddy simulation of combustion in spark ignition engines. Proc. Combust. Inst., 31(2):3059 - 3066, 2007.

34. G. Tabor and H.G. Weller. Large Eddy Simulation of Premixed Turbulent Combustion Using Flame Surface Wrinkling Model. Flow, Turb. and Combust., 72:1-28, 2004.

35. X. Wu, Q. Li, J. Fu, C. Tang, Z. Huang, R. Daniel, G. Tian, and H. Xu. Laminar burning characteristics of 2,5-dimethylfuran and isooctane blend at elevated temperatures and pressures. Fuel, 95:234-240, 2012.

36. R. Bounaceur, F. Battin-Leclerc, O. Herbinet and P-A. Glaude. Modélisation de vitesses de flamme d'un mélange nheptane/isooctane/toluène/éthanol, Contrat de recherche $\mathrm{n}^{\circ} \mathrm{DCP}$ 116 / IFP, 2009.

37. F. Halter, T. Tahtouh and C. Mounaïm-Rousselle. Nonlinear effects of stretch on the flame front propagation, 157, 1825, 2010.

38. C. Ji, E. Dames, Y. L. Wang, H. Wang and F. N. Egolfopoulos. Propagation and extinction of premixed C5-C12 n-alkane flames, Combustion and Flame, 157(2), 277, 2010.

39. R. J. Kee, F. M. Rupley, J. A. Miller, M. E. Coltrin, J. F. Grcar, E. Meeks, H. K. Moffat et al. CHEMKIN Collection, Release 3.6, Reaction Design, Inc., San Diego, CA, 2000.

40. A.P. Kelley, W. Liu, Y.X. Xin, A.J. Smallbone and C.K. Law. Laminar flame speeds, nonpremixed stagnation ignition, and reduced mechanisms in the oxidation of isooctane. Proceedings of the Combustion Institute, 33(1), 501, 2011.

41. C.K. Law. Dynamic of stretched flames. Symposium (international) on Combustion, 22, 1381, 1988.

42. C. K. Law. Propagation, structure, and limit phenomena of laminar flames at elevated pressures, Combustion Science and Technology, 178(1), 335, 2006.

43. X. You, F. N. Egolfopoulos and H. Wang. Detailed and simplified kinetic models of n-dodecane oxidation: The role of fuel cracking in aliphatic hydrocarbon combustion, Proceedings of the Combustion Institute, 32(1), 403, 2009.

44. Z. Zhao. Experimental and Numerical Studies of Burning Velocities and Kinetic Modelling for Practical and Surrogate Fuels. PhD, Department of Mechanical and Aerospace Engineering at Princeton University, 2005.

45. C. Endouard, F. Foucher and F. Halter. Effects of $\mathrm{CO} 2, \mathrm{H} 2 \mathrm{O}$ and EGR dilution on laminar burning velocities and Markstein lengths of isooctane/air mixtures. Ninth Mediterranean Combustion Symposium, Rhodes, Greece, 2015.

46. S. Richard and D. Veynante. A 0-D flame wrinkling equation to describe the turbulent flame surface evolution in SI engines. Comptes Rendus Mécanique, Vol. 343, Issue 3, Pages 219-231, 2015.

47. F. Charlette, C. Meneveau and D. Veynante. A Power-Law Flame Wrinkling Model for LES of Premixed Turbulent Combustion. Part I: Non-Dynamic Formulation and Initial Test. Combustion and Flame, 131 (1-2) (2002), pp. 159-180, 2002.

48. K. Truffin, O. Colin and J.-B. Michel. Simulations LES d'allumage et de propagation de flammes laminaires étirées et turbulente d'isooctane/air. ICAMDAC deliverable L3.2b,c, 2015.

49. M. Metchalchi and J.C. Keck. Burning velocities of mixtures of air with methanol, isooctane, and indolene at high pressure and temperature. Combustion and Flame, 48:191-210, 1982.

50. O.L. Gulder. Burning velocities of ethanol-isooctane blends. Combustion and Flame, 56(3):261-268, 1984.

51. S. Bougrine, S. Richard, A. Nicolle and D. Veynante. Numerical study of laminar flame properties of diluted methane-hydrogenair flames at high pressure and temperature using detailed chemistry. Fuel and Energy, 36(18):12035-12047, 2011.

52. L. de Francqueville. Essais sur monocylindre opaque - Base de données moteur allumage commandé. ICAMDAC deliverable L4.2, 2013.

53. S. Richard, S. Bougrine, G. Font, F.-A. Lafossas and F. Le Berr. On the Reduction of a 3D CFD Combustion Model to Build a Physical 0D Model for Simulating Heat Release, Knock and Pollutants in SI Engines. Oil \& Gas Science and Technology Rev. IFP, Vol. 64 - No. 3, pp. 223-242, 2009.

54. K. Sihling and G. Woschni. Experimental investigation of the instantaneous heat transfer in the cylinder of a high speed Diesel engine, SAE Technical Paper No. 790833, 1979.

55. R.J. Blint. The relationship of the laminar flame width to flame speed, Combustion Science Technology, 49: 79-92, 1986.

\section{Contact Information}

Contact details for the main author should be included here. Details may include mailing address, email address, and/or telephone number (whichever is deemed appropriate).

\section{Acknowledgments}

Thank you MACDOC.

\section{Definitions/Abbreviations}

SA

UBT

test vector sample abbreviations

Use borderless table $\leq 3.5$ inches wide.

Don't capitalize term unless an acronym or proper noun.

Page 19 of 20 


\section{Appendix}

The Appendix is one-column. If you have an appendix in your document, you will need to insert a continuous page break and set the columns to one. If you do not have an appendix in your document, this paragraph can be ignored and the heading and section break deleted.

Page 20 of 20

$10 / 19 / 2016$ 